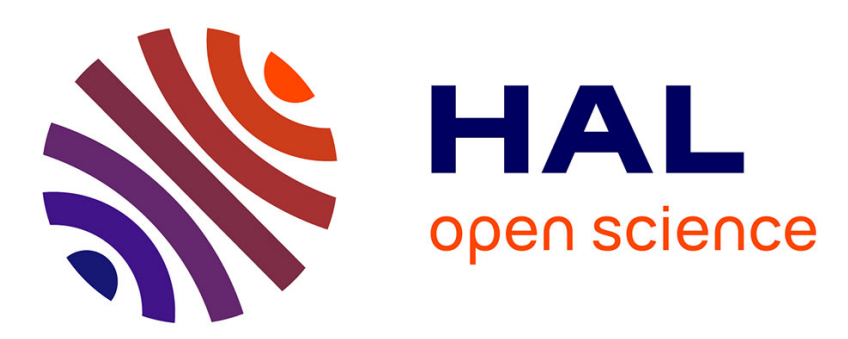

\title{
Recent Advances on Squaraine-based Photoinitiators of Polymerization
}

\author{
Nicolas Giacoletto, Malika Ibrahim-Ouali, Frédéric Dumur
}

\section{To cite this version:}

Nicolas Giacoletto, Malika Ibrahim-Ouali, Frédéric Dumur. Recent Advances on Squarainebased Photoinitiators of Polymerization. European Polymer Journal, 2021, 150, pp.110427. 10.1016/j.eurpolymj.2021.110427 . hal-03193734

\section{HAL Id: hal-03193734 \\ https://hal.science/hal-03193734}

Submitted on 9 Apr 2021

HAL is a multi-disciplinary open access archive for the deposit and dissemination of scientific research documents, whether they are published or not. The documents may come from teaching and research institutions in France or abroad, or from public or private research centers.
L'archive ouverte pluridisciplinaire HAL, est destinée au dépôt et à la diffusion de documents scientifiques de niveau recherche, publiés ou non, émanant des établissements d'enseignement et de recherche français ou étrangers, des laboratoires publics ou privés. 


\title{
Recent Advances on Squaraine-based Photoinitiators of Polymerization
}

\author{
Nicolas Giacoletto ${ }^{a}$, Malika Ibrahim-Oualib ${ }^{b}$ Frédéric Dumura* \\ a Aix Marseille Univ, CNRS, ICR, UMR 7273, F-13397 Marseille, France \\ b Aix Marseille Univ, CNRS, Centrale Marseille, iSm2, F-13397 Marseille, France \\ frederic.dumur@univ-amu.fr
}

\begin{abstract}
The development of photoinitiating systems activable in the visible and the nearinfrared region is an active research field. Compared to the traditional UV photopolymerization for which the light penetration into the photocurable resin remains limited, a significant enhancement of this latter can be obtained in the visible and the near infrared range so that the scope of applications of photopolymerization can be revolutionized. Among dyes whose absorption can be facilely tuned, squaraines can be cited as relevant examples. Depending on the peripheral groups introduced on both sides of the central fourmembered squaric ring, absorptions ranging from 400 to $1000 \mathrm{~nm}$ can be obtained. In this review, an overview of the recent development concerning the squaraines-based photoinitiating systems is provided. To evidence the interest of these new photoinitiating systems, comparisons with reference systems will be established.
\end{abstract}

\section{Keywords}

Photoinitiator; squaraine; photopolymerization; squarilium; NIR; LED

\section{Introduction}

During the past decades, a great deal of efforts has been devoted to develop visible light photoinitiators of polymerization.[1-13] This intense research effort is notably supported by the recent safety concerns raised by the use of UV light, but also by the high cost and the high energy consumption of the UV irradiation setups so that alternatives of this historical polymerization approach are actively researched.[14-20] Logically, the design of visible light photoinitiator has emerged as a promising alternative and this research topic is now an active research field. However, if the approach is appealing, numerous drawbacks remain to overcome. Indeed, dyes such as titanocenes and borate dyestuffs were developed long time ago as visible photoinitiators of polymerization.[21-23] However, these compounds did not find a widespread use in industry due to the difficulty to handle, these resins requiring to be manipulated in the exclusion of light. A lot of works has thus still to be done in terms of molecular engineering in order the visible light technology to be transferred in industry. Recently, light-emitting diodes (LEDs) have emerged as cheap, lightweight, compact and tunable light sources so that visible light photopolymerization has greatly benefited from this development.[24-25] The easy access to cheap visible light sources has also drastically increased the demand for visible light photoinitiating systems.[26] Notably, LEDs emitting at 
$405 \mathrm{~nm}$ are commonly used in 3D printing so that this technological innovation has given a revival of interest to photopolymerization and especially to the development of photoinitiators activable at $405 \mathrm{~nm}$.[27-31] If photopolymerization remains less studied that the thermal polymerization, this polymerization technique exhibits however several advantages. Notably and contrarily to thermal polymerization, a spatial and a temporal control can be achieved, meaning that the polymerization process occurs only in the irradiated zone and during the time the surface is exposed to light. Another great advantage of photopolymerization relies in the possibility to polymerize without solvent, avoiding the release of volatile organic compounds (VOCs). From this viewpoint, photopolymerization can be considered as a greener polymerization technique than the thermal polymerization requiring solvents for the synthesis but also for the purification of the polymers. Considering the ever-growing efforts to develop more efficient visible light photoinitiators, a wide range of families have been examined over the years, as exemplified with camphorquinones,[32,33] diketopyrrolopyrroles,[34-36] chromones,[37-39] dihydroanthraquinones,[40] coumarins,[41-47] iridium complexes, [48-56] phenothiazines, [57] cyanines, [58-59] squaraines,[60-61] iodonium salts, [62-64] acridones,[6566] 2,3-diphenylquinoxaline derivatives,[67] pyrenes, [68-73] zinc complexes, [74] naphthalimides,[75-87] cyclohexanones,[88-91] carbazoles,[92-97] benzophenones,[98-103] thioxanthones,[104-107] flavones,[108] acridine-1,8-diones,[109-111] perylenes, [112-114] copper complexes,[115-125] helicenes,[126-127] chalcones,[128-136] push-pull dyes[137-148] porphyrins,[149-150] and iron complexes.[151-156] If the molar extinction coefficient can impact the polymerization efficiency as this parameter governs the ability of the chromophore to absorb light, position of the absorption maximum is another parameter of crucial importance as the light penetration within the photocurable resin is directly linked to the wavelength used to excite the resins. As shown in the Figure 1, if the light penetration is low at $300 \mathrm{~nm}$ (around $600 \mu \mathrm{m}$ ) i.e. in the UV range, conversely, this latter can range between 4 $\mathrm{mm}$ to $5 \mathrm{~cm}$ for an irradiation done in the visible range.[59] It therefore supports the recent interest for visible light polymerization processes since a revolution is currently under progress. If historically, photopolymerization was devoted to the elaboration of thin films due to the weak light penetration in the UV range, shift of the excitation from the UV region towards the near infrared (NIR) range enables now to polymerize thick samples, but also filled polymers.[157-159]

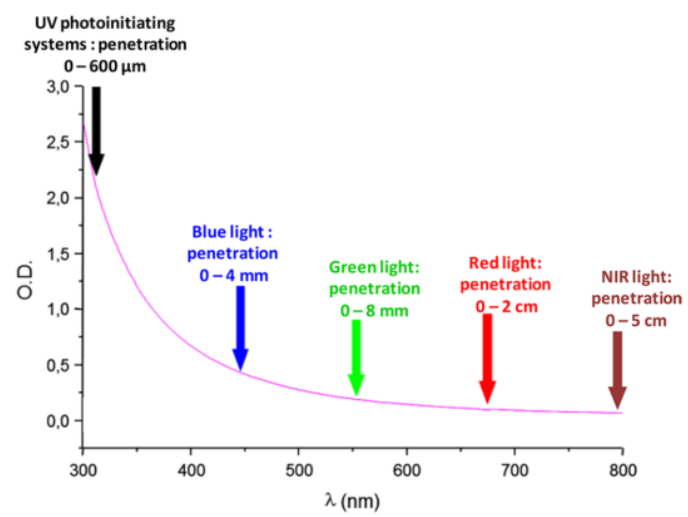

Figure 1. Light penetration in a polystyrene latex with an average diameter of $112 \mathrm{~nm}$. Reproduced with permission from Bonardi et al. [49]. Copyright 2018 American Chemical Society. 
Efficiency of the polymerization process is also strongly related to the strategy used to generate radicals. Indeed, two different types of photoinitiators exist. The first family of photoinitiators named Type I photoinitiators consists in chemical structures that can cleave upon photoexcitation (See Figure 2). These molecules can be used as single component photoinitiating systems. However, photocleavage of the structures is irreversible so that the photosensitizer concentration continuously decreases over time.[160-163]

Type I photoinitiators

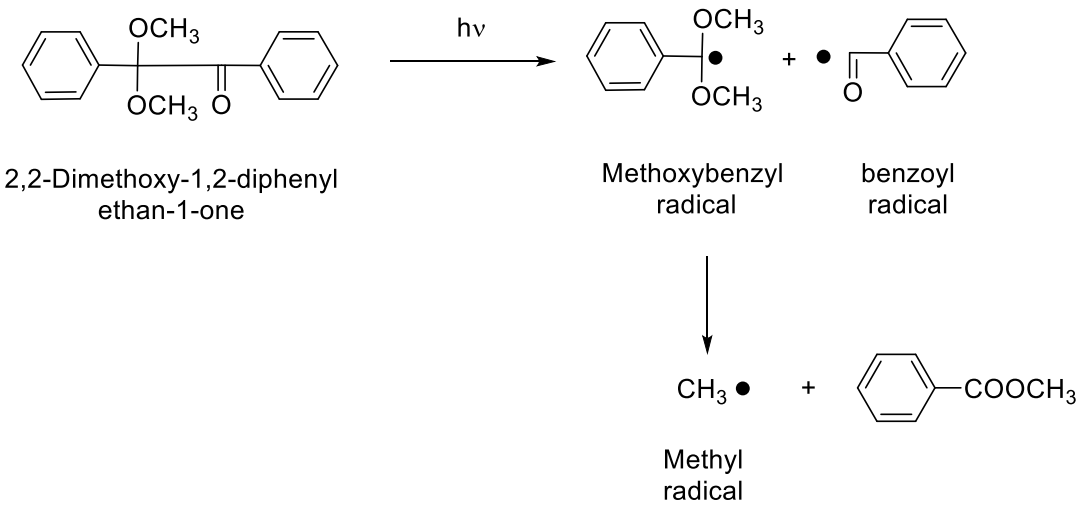

Type II photoinitiators
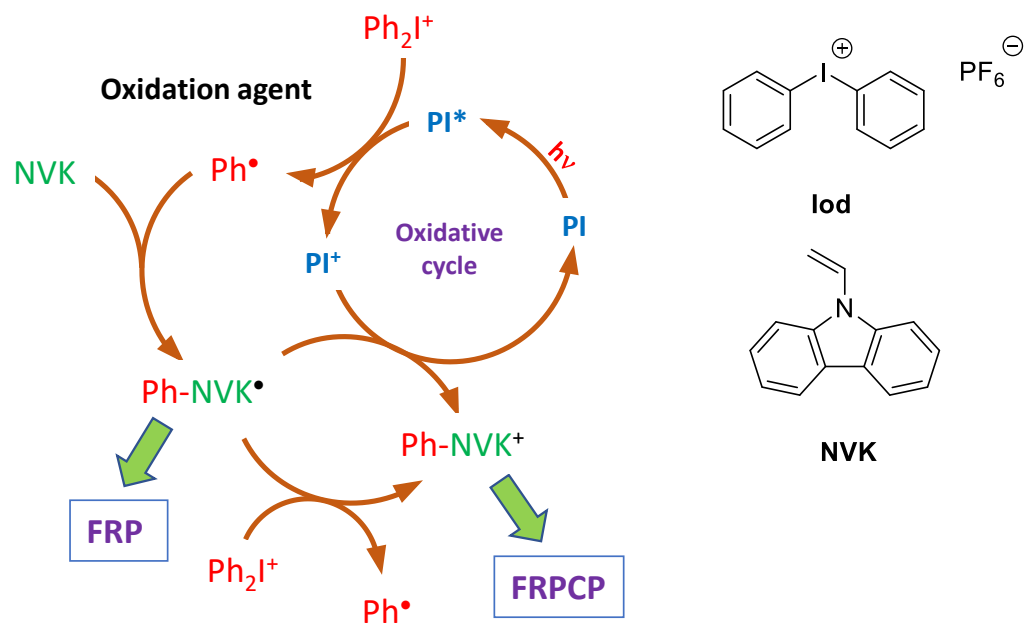

Figure 2. The two families of photoinitiators reported in the literature.

On the opposite, photocatalytic systems can be developed with Type II photoinitiators.[164-166] Indeed, as shown in the Figure 2, upon photoexcitation, the photosensitizer is promoted in its excited state, inducing an electron transfer towards the electron acceptor i.e. the iodonium salt. By decomposition of this latter, phenyl radicals $\mathrm{Ph} \bullet$ are formed, enabling to initiate the free radical polymerization (FRP) of acrylates. Using this twocomponent system, the photosensitizer is irreversibly oxidized as a radical cation, reducing the ability for the photocurable resin to harvest light. To address this issue, a sacrificial amine can be introduced as a third component. Using this strategy, the photosensitizer can be regenerated in its initial redox state by redox reaction with the sacrificial amine. However, 
when $\mathrm{N}$-vinylcarbazole (NVK) is used, phenyl radicals $\mathrm{Ph}^{\bullet}$ can also add onto the amine, generating $\mathrm{Ph}-\mathrm{NVK} \bullet$ that are more reactive than the initial phenyl radicals. Upon reduction of the oxidized photosensitizer, $\mathrm{Ph}-\mathrm{NVK}^{+}$can be formed, converting the initial radical polymerization process to a cationic one. Thus, the free radical promoted cationic polymerization (FRPCP) of epoxides is thus possible. Considering that the two polymerization modes can concomitantly exist, the preparation of interpenetrated networks resulting from the simultaneous polymerization of acrylates and epoxides is thus possible using this approach.[167-170]

Concerning dyes whose absorption spectra can be efficiently tune over the visible range, squaraines are one of those. These dyes that are sometimes named squarilium due to their zwitterionic structures are composed of a central four-membered ring derived from squaric acid that is substituted at both ends with various electron donating groups. Benefiting from this versatility, squaraines have been extensively used in applications such as solar cells,[171-174] colorimetric sensing,[175-176] photothermal therapy[177-178] and imaging.[179-181] Squaraines whose synthesis has been first reported in 1965[182] have seen their chemical structures to drastically evolve since these pioneering works and 1,2- and 1,3squaraines, symmetrical and asymmetrically substituted structures can be now selectively prepared. Notably, if the synthesis of 1,3-squaraines is known since decades, the regioselective synthesis of 1,2-squaraines has only been developed in 2011, explaining still the scarcity of the family of squaraines.[183-186] In fact, if the design of squaraines has been studied for various research fields, their use as visible light photoinitiators of polymerization has only been recently reported, the first report being published in 2004 [187] (See Figure 3). However, since 2016, squaraines have been more extensively studied as photoinitiators of polymerization by various research groups.<smiles>[R]c1c([O-])c(=O)c1=O</smiles><smiles>[R]C=c1c(=O)c(=O)c1=C[R]</smiles>

Figure 3. General structure of squaraines

Compared to the families of dyes previously discussed, squaraine-based photoinitiating systems exhibit several advantages and disadvantages that are listed in the Table 1

Table 1. Comparisons between ferrocene-based photoinitiating systems and other photoinitiating systems.

\begin{tabular}{|c|c|c|}
\hline Parameters & $\begin{array}{c}\text { Squaraine-based } \\
\text { photoinitiating systems }\end{array}$ & other organic dyes \\
\hline Cost/synthesis & $\begin{array}{c}\text { Squaraine can be prepared } \\
\text { from squaric acid or squarates } \\
\text { which are commercially } \\
\text { available. Squaraines are also } \\
\text { highly soluble in common }\end{array}$ & $\begin{array}{c}\text { Depending of the families of } \\
\text { dyes, starting compounds } \\
\text { can be expensive. Solubility } \\
\text { is highly dependent of the } \\
\text { family of dyes selected as }\end{array}$ \\
\hline
\end{tabular}




\begin{tabular}{|c|c|c|}
\hline & $\begin{array}{c}\text { organic solvents contrarily to } \\
\text { 1,3-bis(arylamino)squaraines } \\
\text { which exhibit a more limited } \\
\text { solublity. }\end{array}$ & $\begin{array}{l}\text { structures, but also from the } \\
\text { substitution pattern. }\end{array}$ \\
\hline Environmental impact & $\begin{array}{l}\text { squaraines can be purified by } \\
\text { column chromatography or by } \\
\text { recrystallization, depending of } \\
\text { the substitution pattern }\end{array}$ & $\begin{array}{l}\text { The same purification } \\
\text { procedures can be } \\
\text { developed than that done } \\
\text { for squaraine derivatives }\end{array}$ \\
\hline Photochemical stability & $\begin{array}{l}\text { squaraines are } \\
\text { photochemically stable. } \\
\text { Notably, these dyes are } \\
\text { extensively studied as light- } \\
\text { absorbing materials for solar } \\
\text { cells }\end{array}$ & $\begin{array}{l}\text { Synthetic dyes can also be } \\
\text { photochemically stable. }\end{array}$ \\
\hline Absorption range & $\begin{array}{c}\text { Absorption spectra of } \\
\text { squaraines can be easily } \\
\text { tuned. Dyes absorbing over } \\
\text { the whole visible range can be } \\
\text { obtained. }\end{array}$ & $\begin{array}{l}\text { The same holds true for } \\
\text { synthetic dyes. }\end{array}$ \\
\hline Photoinitiating ability & $\begin{array}{c}\text { Squaraines can compete with } \\
\text { benchmark photoinitiators. }\end{array}$ & $\begin{array}{l}\text { The same holds true for } \\
\text { synthetic dyes. }\end{array}$ \\
\hline Availability & $\begin{array}{l}\text { Squaraines are easily } \\
\text { accessible, especially from } \\
\text { suppliers specialized in } \\
\text { compounds devoted to } \\
\text { Organic Electronics }\end{array}$ & $\begin{array}{l}\text { Chemicals used to elaborate } \\
\text { dyes are also benchmarked. } \\
\text { The limitation can be the } \\
\text { cost for some of the starting } \\
\text { materials. }\end{array}$ \\
\hline Bioactivity & $\begin{array}{c}\text { Squaraines can exhibit } \\
\text { biological activities[188-193] }\end{array}$ & $\begin{array}{l}\text { Synthetic dyes can also } \\
\text { exhibit biological activities. }\end{array}$ \\
\hline
\end{tabular}

In this review, an overview of the different squaraines-based photoinitiating systems developed to date is reported. To evidence the interest of these new structures, comparisons with benchmark photoinitiators will be established.

\section{Squaraines as visible light photoinitiators}

\subsection{First use of squaraines as photoinitiators}

The design of visible light photoinitiating systems is the subject of intense research efforts since decades. The first report mentioning the use of squaraines as visible light photoinitiators of polymerization has been reported as soon as 2004 by Wang and coworkers.[187] Squaraines are characterized by very short excited singlet state lifetimes and very low intersystem crossing quantum yields so that their use in diffusion-controlled bimolecular reactions is difficult. Indeed, most of the photoinitiating systems are based on the photoreduction or the photooxidation of the photosensitizer which reacts in its excited state with the coinitiator.[194] In the case of viscous monomers, diffusion of the photosensitizer and 
the coinitiator are largely impeded, adversely affecting the formation of initiating species. To address this issue, the formation of photoinitiating systems in which the photosensitizer and the coinitiator can interact by mean of electrostatic interactions is a great advantage. Such a goal can be obtained with squaraines for which a negative charge located onto the oxygen atom of the four-membered ring can be clearly evidenced by theoretical calculations.[195-196] Therefore, the central core of squaraines is negatively charged. Conversely, iodonium salts are positively charged with a positive charge located onto the iodine atom. Considering the presence of opposite charges, electrostatic interactions can occur between the two partners (squaraines and iodonium salts). This strategy is not new since it has previously been applied to create Xanthen dye/iodonium pairs.[197-198] As shown in the Figure 4, bis(1,2,3,3tetramethylindolenium-2-ylidene)squaraine (SQP) and bis(3-methylbenzothiazol-2-ylidene) squaraine (SQT) both exhibit absorption maxima located at $632 \mathrm{~nm}$ whereas the absorption maxima of the different diphenyliodonium salts (Iod1-Iod3) which only differ by the counteranions (hexafluorophosphate $\left(\mathrm{PF}_{6}\right)$, hexafluoroantimonate $\left(\mathrm{SbF}_{6}\right)$ and para-toluenesulfonate (TsO-) respectively) are located at $227 \mathrm{~nm}$ (See chemical structures in Figure 5). Therefore, upon excitation in the visible range with a $400 \mathrm{~W}$ Xenon lamp, only SQP and SQP can absorb light.

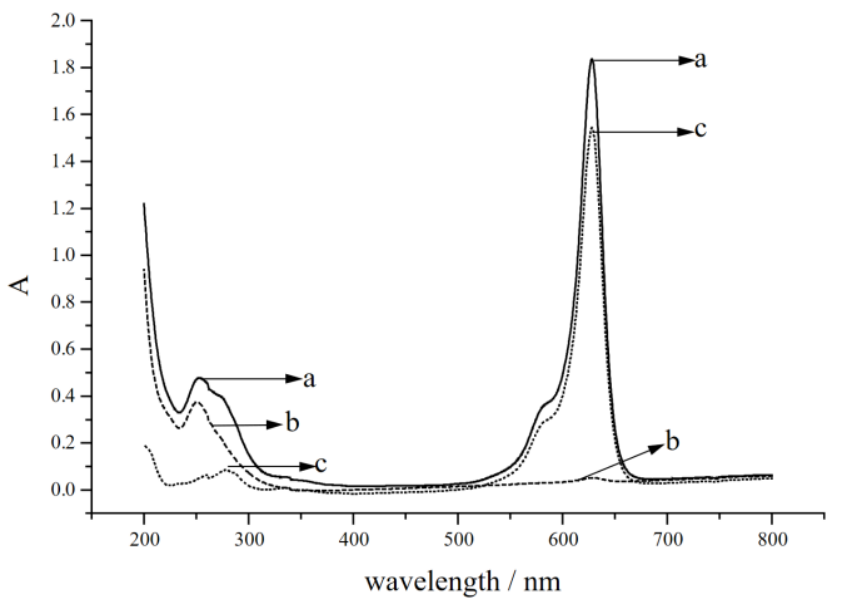

Figure 4. UV-visible absorption spectra of (a) Iod2 + SQP, (b) Iod1, (c) SQP. Reproduced with permission from Ref. [187]

Photolysis experiments done with the SQP/Iod2 and the SQT/Iod2 combinations in acetonitrile revealed the photolysis process to be faster with SQT than with SQP, resulting from a faster photoinduced electron transfer rate in the case of SQT. Different photobleaching rates were also determined, depending on the counter-anions. Thus, the order of reactivity was established for the iodonium salts: $\operatorname{Iod} 2>\operatorname{Iod} 1>\operatorname{Iod} 3$. Indeed, in the case of large counteranions, the ion-pair dissociation is facilitated due to a diffused negative charge on the anion and the lower nucleophilicity of the anion. Comparison of the photolysis experiments done under inert atmosphere and under air revealed the photobleaching rate to be similar, demonstrating that the squaraines/iodonium interaction was occurring via the singlet excited state of squaraines. Photopolymerization experiments of methyl methacrylate (MMA) using the two-component squaraines/iodonium salts combinations revealed the two squaraines to photosensitize the polymerization process. In acetonitrile and under air, kinetics of polymerization remained however slow since a final monomer conversion of $14 \%$ after 200 
minutes of irradiation could be obtained for the optimized conditions with the SQT/Iod2 combination. Logically, upon increase of the squaraines concentration, a decrease of the monomer conversion was evidenced, resulting from light screening effects of the dyes. Indeed, by increasing the dye concentration, an increase of the optical density occurs, impeding light penetration within the resin. Conversely, in thin films, faster polymerization processes were evidenced during the free radical polymerization (FRP) of an epoxy-acrylate resin (CN 124)/TMPTA blend.

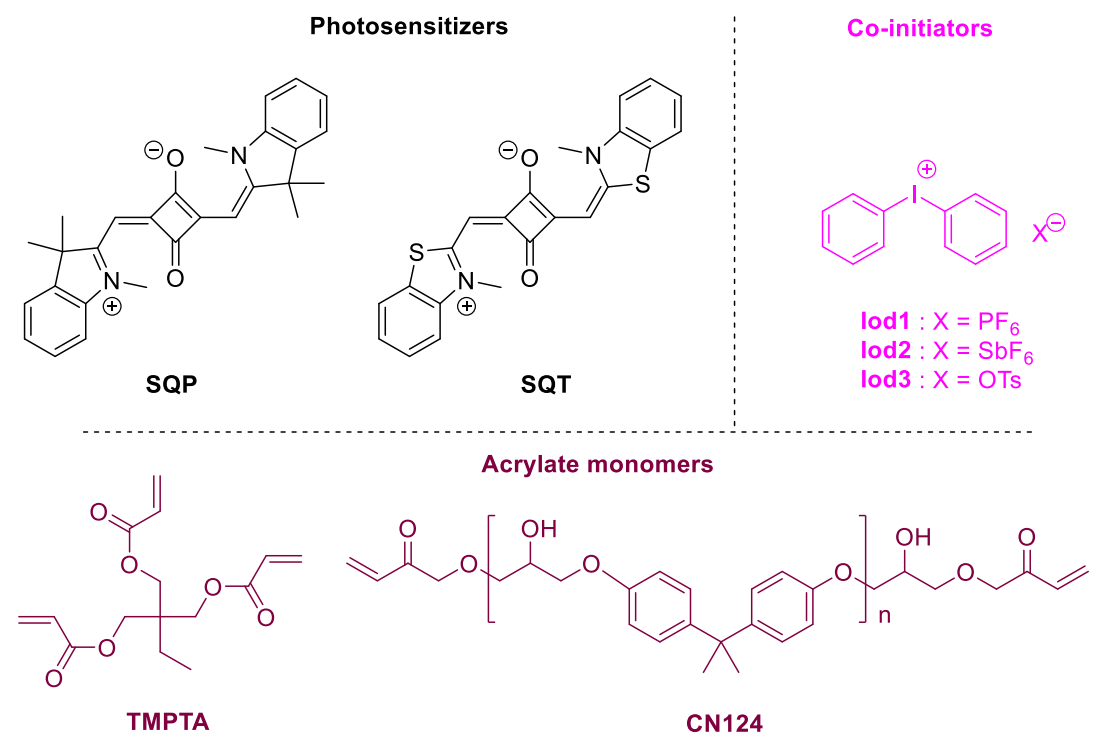

Figure 5. Chemical structures of SQP and SQT, the different monomers and additives.

Using the two-component squaraines/Iod2 (1\%/2\% w/w) systems, identical photoinitiating abilities were found for the two squaraines, the monomer conversion kinetic curves overlapping for the two dyes. After $25 \mathrm{~s}$ of irradiation, a final monomer conversion of $35 \%$ could be determined for the polymer blend. Finally, to support the polymerization process and the generation of radicals, two mechanisms were proposed, one based on the electrostatic interactions between the squaraines and the iodonium salts, and a second one based on a traditional bimolecular interaction (See Figure 6).

$$
\begin{aligned}
& \text { pathway I } \mathrm{SQ}^{-} \mathrm{On}^{+} \underset{\mathrm{k}_{\mathrm{d}}}{\stackrel{\mathrm{hv}}{\rightleftharpoons}}\left(\mathrm{SQ}^{-} \mathrm{On}^{+}\right)^{*} \frac{\mathrm{k}_{\mathrm{e}}}{-\mathrm{k}_{\mathrm{e}}} \mathrm{SQ} \bullet / \mathrm{On} \bullet \longrightarrow \\
& \text { \| }
\end{aligned}
$$

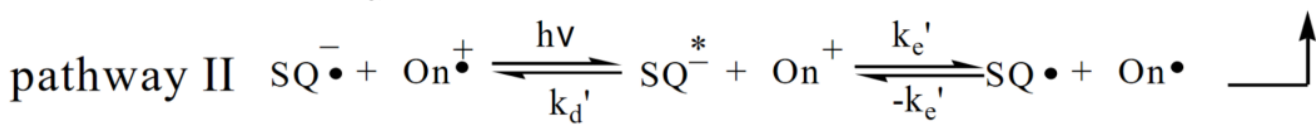

Figure 6. The two chemical mechanisms proposed to support the FRP of acrylates with SQP and SQT. The acronym "On" stands for onium salts. Reproduced with permission from Ref. 


\section{2. $\quad 1,3-B i s($ arylamino)squaraines}

After twelve years of disinterest for squaraines as visible light photoinitiators of polymerization, these structures were revisited starting from 2016 by the group of Kabatc and coworkers who developed several works devoted to 1,3-bis(arylamino)squaraines.[199] The first work notably focused on the simplest structure of the series, namely, 1,3bis(phenylamino)squaraines SQ1 (See Figure 7). An update was this work was also proposed in 2017.[200]

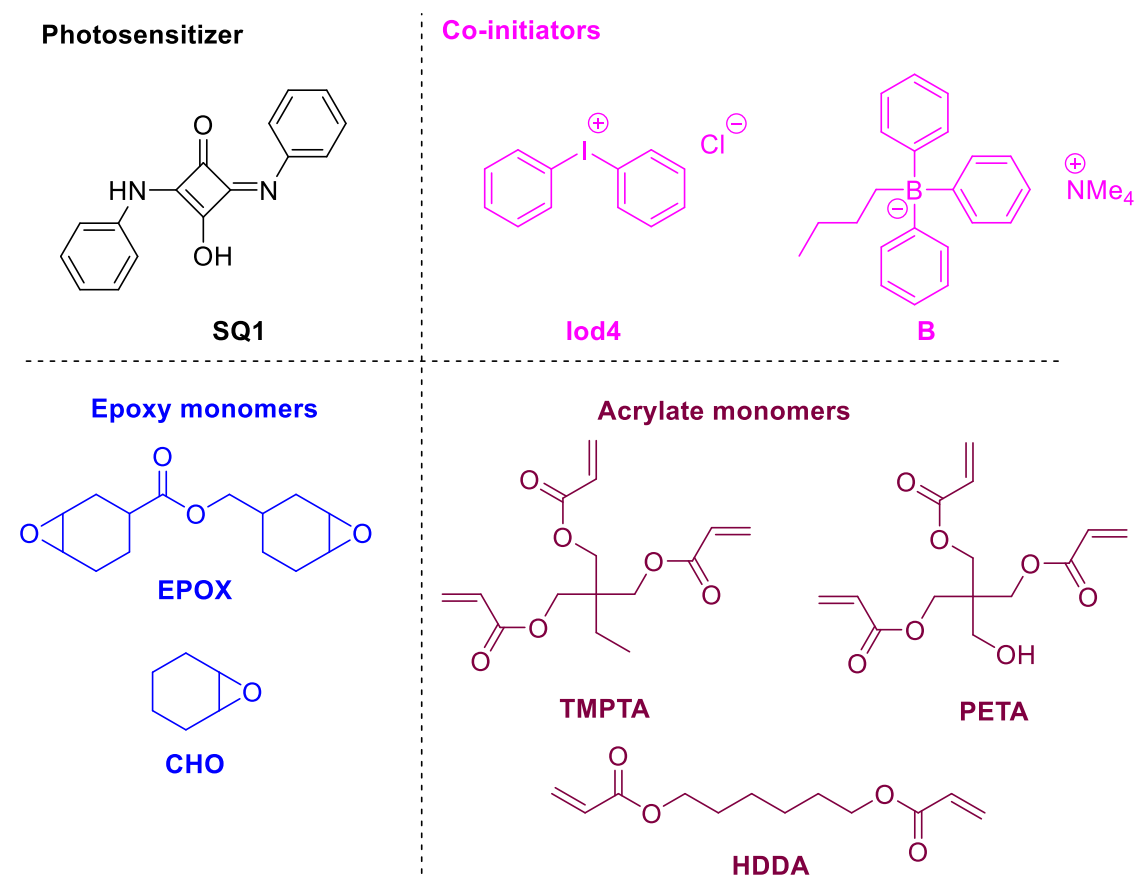

Figure 7. Chemical structure of SQ1, co-initiators, epoxy and acrylate monomers.

Onium salts are efficient photoinitiators, but direct excitation of these structures can only be done at wavelength lower than $290 \mathrm{~nm}$. To overcome this problem when visible light sources are used, a simple and flexible method consists in using a photosensitizer that will absorb light instead of the UV photoinitiator and by electron transfer in the excited state between the photosensitizer and the photoinitiator, a decomposition of the UV photoinitiator can occur, enabling the polymerization process to proceed. This strategy was notably applied with SQ1, used for the sensitization of two diphenyliodonium salts. Indeed, iodonium salts are capable to both initiate a free radical and a cationic polymerization.[201] These salts also exhibit a remarkable solubility in most of the cationic polymerizable monomers, a good thermal stability so that iodonium salts are extensively used in photopolymerization. The same hold true for alkyltriphenylborate whose decomposition can only be initiated for irradiation below $300 \mathrm{~nm}$. Thus, 1,3-bis(phenylamino)squaraine SQ1 which absorbs between 350 and 450 $\mathrm{nm}$ was determined as being a suitable candidate for the photosensitization of the two diphenyliodonium salts (Iod1 and $\operatorname{Iod} 4)$ and tetramethylammonium $n$-butyltriphenylborate $\mathrm{B}$ (See Figure 7).

Fluorescence quenching experiments revealed the interaction between the photosensitizer and the co-initiators to be diffusion controlled, ranging between 2 and $6 \times 10^{10}$ 
$\mathrm{M}^{-1} \cdot \mathrm{s}^{-1}$. Comparison between the rate constants of quenching revealed the constants with the borate salt to be higher than for the iodonium salts. Similarly, a higher rate constant of quenching could be determined for the chloride salt compared to the hexafluorophosphate salt due to a better access to the cation when a small anion is used. Photopolymerization experiments carried out upon irradiation in the $300-500 \mathrm{~nm}$ range $\left(\mathrm{I}=30 \mathrm{~mW} / \mathrm{cm}^{2}\right)$ revealed the FRP of acrylates to be highly dependent of the decomposition rate constant of co-initiators. Thus, for pentaerythritol triacrylate (PETA), the highest final monomer conversion was obtained with diphenyliodonium chloride (Iod4), with a three-fold enhancement of the monomer conversion compared to that obtained with diphenyliodonium hexafluorophosphate (Iod1) (17.5\% vs. 6.9\% monomer conversions). Conversely, for 1,6hexanediol diacrylate (HDDA) and pentaerythritol triacrylate (PETA), best monomer conversions were obtained with tetramethylammonium n-butyltriphenylborate (B), the conversions peaking at $27.3 \%$ and $21.6 \%$ respectively, after 10 minutes of irradiation. Comparison with other photoinitiating systems based on squaraines, namely bis (1,2,3,3tetramethylindolenium-2-ylidene) squaraine (SQP) and bis(3-methylbenzothiazol-2-ylidene) squaraine (SQT) revealed the SQ1-based photoinitiating system to outperform the SQP and the SQT-based systems (See Figure 5).[202] Indeed, in this last case, only monomer conversions ranging between 10 and $14 \%$ could be obtained after four hours of irradiation with the squaraines/iodonium two-component systems. While examining the polymerization of epoxides, all systems proved to be ineffective for the polymerization of 3,4epoxycyclohexylmethyl-3,4-epoxycyclohexanecarboxylate (EPOX) whereas cyclohexene oxide $(\mathrm{CHO})$ could only be polymerized with the two-component SQ1/Iod1 system. In this last case, a monomer conversion of $70 \%$ could be obtained after $60 \mathrm{~min}$. of irradiation in the 300$500 \mathrm{~nm}$ range $\left(\mathrm{I}=30 \mathrm{~mW} / \mathrm{cm}^{2}\right)$. To support the polymerization of $\mathrm{CHO}$, the remarkable hydrogen donating ability of this monomer compared to that of EPOX was suggested as playing a key-role in the polymerization process.[196] Therefore, it could be concluded that the $\mathrm{CP}$ was occurring according to a hydrogen abstraction process of $\mathrm{CHO}$ by the cationic radicals of SQ1. In 2016, a similar study was developed with 1,3-bis(pbromophenylamino)squaraine (SQ2). Thanks to the presence of bromine, a redshift of the absorption spectrum could be clearly evidenced, the absorption maximum peaking at $415 \mathrm{~nm}$ for SQ2 vs $400 \mathrm{~nm}$ for SQ1.[203] Using the same additives, fluorescence quenching experiments revealed the interaction process for the SQ2/Iod4, SQ2/Iod1 and SQ2/B combinations to be diffusion-controlled. For the polymerization tests, another additive was also used, namely $\mathrm{N}$-methoxy-4-phenylpyridinium tetrafluoroborate (NO), which proved to be the best coinitiator in terms of polymerization speed and final monomer conversion (See Figure 8). The highest monomer conversion was obtained with 1,6-hexanediol diacrylate (HDDA) as the monomer and reached $73 \%$ after 10 minutes of irradiation in the $300-500 \mathrm{~nm}$ range $\left(\mathrm{I}=30 \mathrm{~mW} / \mathrm{cm}^{2}\right)$ for the two-component SQ2/NO. If the polymerization speed was higher with $\mathrm{NO}$, the final monomer conversion was comparable to that obtained with Iod4. 

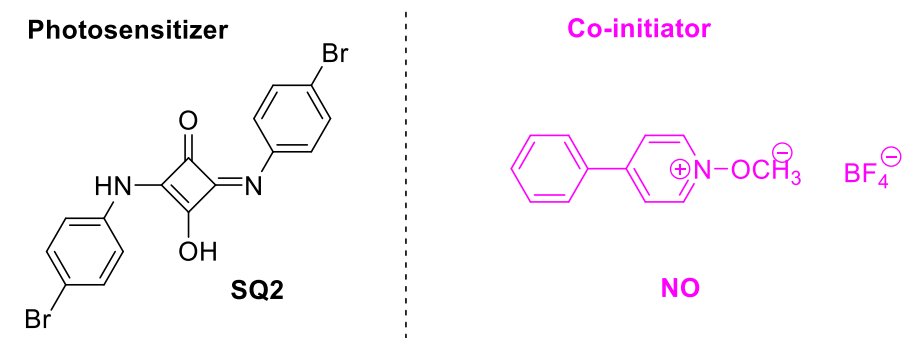

Figure 8. Chemical structure of 1,3-bis(p-bromophenylamino)squaraine (SQ2) and Nmethoxy-4-phenylpyridinium tetrafluoroborate (NO).

Remarkably, if a two-fold enhancement of the monomer conversion was observed in pentaerythritol triacrylate (PETA) for the two-component SQ2/NO system compared to the borate-based two-component SQ2/B system (45 vs 23\% respectively), this difference even increased in TMPTA, and a 7-fold enhancement of the monomer conversion could be detected in this monomer (47 vs. $7 \%$ respectively) (See Figure 9). Comparisons with the reference twocomponent camphorquinone/Iod1 system revealed the polymerization of TMPTA under visible light to only reach $18 \%$ in the same conditions,[204] demonstrating the efficiency of the two-component SQ2/NO system (47\% monomer conversion) reported in this work. Investigation of the chemical mechanism revealed that in the case of Iod4 and NO, SQ2 was oxidized during the photoexcitation process contrarily to that observed with the borate anion B. In this last case, SQ2 was determined as being reduced. Following the electron transfer, the radicals thus formed can undergo a fast and irreversible fragmentation resulting from carboniodide, carbon-boron or nitrogen-oxygen bond cleavages (See Figure 10).
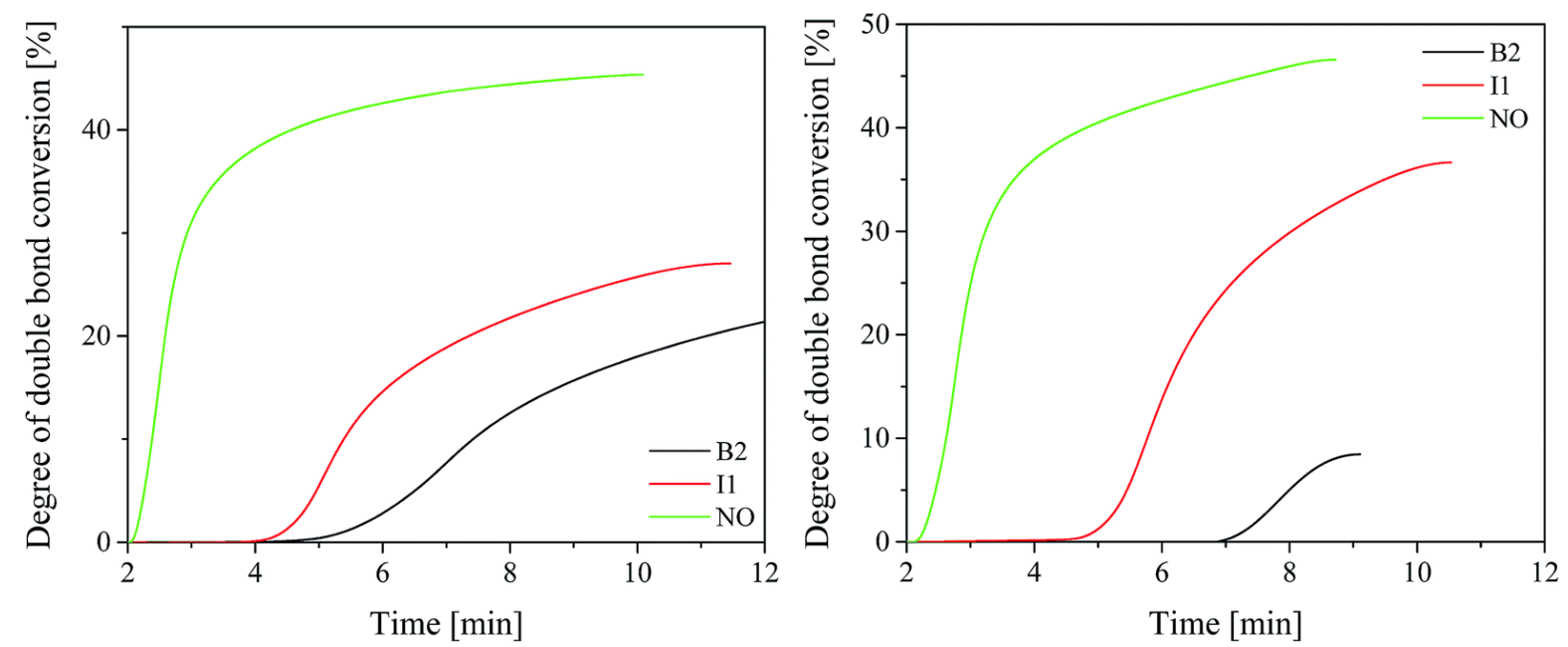

Figure 9. Kinetics of monomer conversions in PETA (left) and TMPTA (right) using twocomponent SQ2/additives systems upon irradiation in the visible range, $30 \mathrm{~mW} / \mathrm{cm}^{2}$; [SQ2] = $2 \times 10^{-3} \mathrm{M}$; [co-initiator] $=2 \times 10^{-3} \mathrm{M}$. Reproduced with permission of Ref. [203]. 


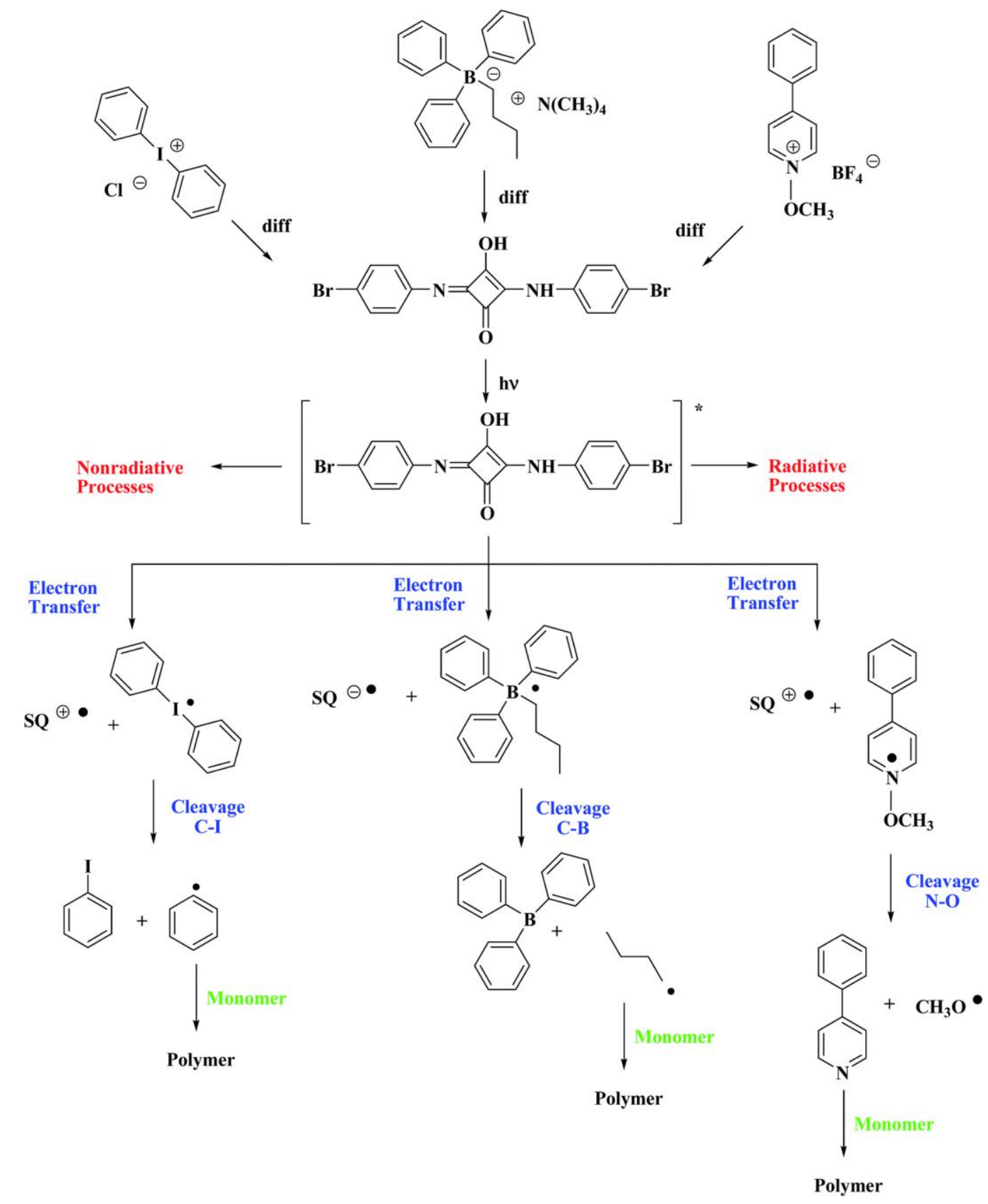

Figure 10. Chemical mechanism supporting the polymerization of acrylates upon visible light irradiation. Reproduced with permission of Ref. [203]

Following this work, SQ2 was revisited in a second study in which a broader range of co-initiators was examined.[205] Notably, fourteen two-component systems based on SQ2 as the photosensitizer and various iodonium salts (Iod1, I77-I81, I83-I87, I90, I92 and I93) as coinitiators were examined (See Figure 11). 
<smiles>COc1ccc([Hg]([O])c2ccccc2)cc1</smiles>

177<smiles>COc1ccc([Al]([O])c2ccc(Cl)cc2)cc1</smiles>

180<smiles>COc1ccc([Al]([O])c2ccc(C)cc2)cc1</smiles>

178<smiles>COc1ccc([I-]([O])c2ccc(C#N)cc2)cc1</smiles>

179<smiles>COc1ccc([Al]([O])c2ccc([N+](=O)[O-])cc2)cc1</smiles>

181<smiles>COc1ccc(I(C)c2ccccc2OC)cc1</smiles>

183<smiles>COc1ccc([SiH]([O])c2ccc(Br)cc2)cc1</smiles>

184<smiles>COc1ccc([Al]([O])c2ccc(C(F)(F)F)cc2)cc1</smiles>

185<smiles>COc1ccc([Te](c2ccccc2C(F)(F)F)c2ccccc2C(F)(F)F)cc1</smiles>

186<smiles>COc1ccc([Al]([O])c2cccc(C(F)(F)F)c2)cc1</smiles>

187<smiles>COc1ccc([Al]([O])c2ccc(C(C)(C)C)cc2)cc1</smiles>

192<smiles>COc1ccc([Al]([O])c2ccc(OC)cc2)cc1</smiles>

190<smiles>COc1ccc([Al]([O])c2ccc(F)cc2)cc1</smiles>

193<smiles>Cc1ccc(S(=O)(=O)[O-])cc1</smiles>

Figure 11. Chemical structures of the 13 iodonium salts examined as co-initiators with SQ2.

If abilities of the different two-component systems to initiate the FRP of TMPTA were relatively similar, besides, a 40 -fold increase of the photoinitiator concentration resulted in a 2-to a 4-fold increase of the polymerization rate, irrespective of the iodonium salts. However, by increasing the concentration of the photosensitizers from $5 \times 10^{-4} \mathrm{M}$ to $2 \times 10^{-3} \mathrm{M}$, the polymerization efficiency reached a maximum, resulting from inter filter effects. Interestingly, introduction of a nitro group onto I81 could induce a significant increase of the final monomer conversion as well as the polymerization rate. Thus, at the concentration of $1 \times 10^{-2} \mathrm{M}$ for SQ2, final TMPTA conversions ranging from $11 \%$ to $42 \%$ could be respectively determined with the two-component SQ2/I90 and SQ2/I81 systems. Following I81, the best monomer conversions were obtained with the two-component systems based on I79 and I86, peaking at $28 \%$ with the two photoinitiating systems comprising I79 and I86, the monomer conversions peaking at $28 \%$. As specificity, I79 and I86 are substituted in a similar way to that of I81, with electronwithdrawing groups (a cyano group for $\mathrm{I79}$ and a $\mathrm{CF}_{3}$ group for I86). Surprisingly, the authors assigned the improved performance of I81 to a higher solubility of this iodonium salt compared to the others. Besides, good photoinitiating abilities are observed for all iodonium salts substituted with electron-withdrawing groups, supporting the presence of electronic effects in the photoinitiation process. Finally, comparisons with reference photoinitiating 
systems based on camphorquinone revealed the SQ2/I81 system to be less efficient than benchmarked two-component systems such as the camphorquinone (CQ)/ethyl p(dimethylamino)benzoate, camphorquinone/ $\mathrm{N}$-methyldiethanolamine or camphorquinone/ $N$-phenylglycine combinations (See Figure 12). As a unique exception, only the SQ2/I81 combination could outperform the two-component camphorquinone/Iod4 system.

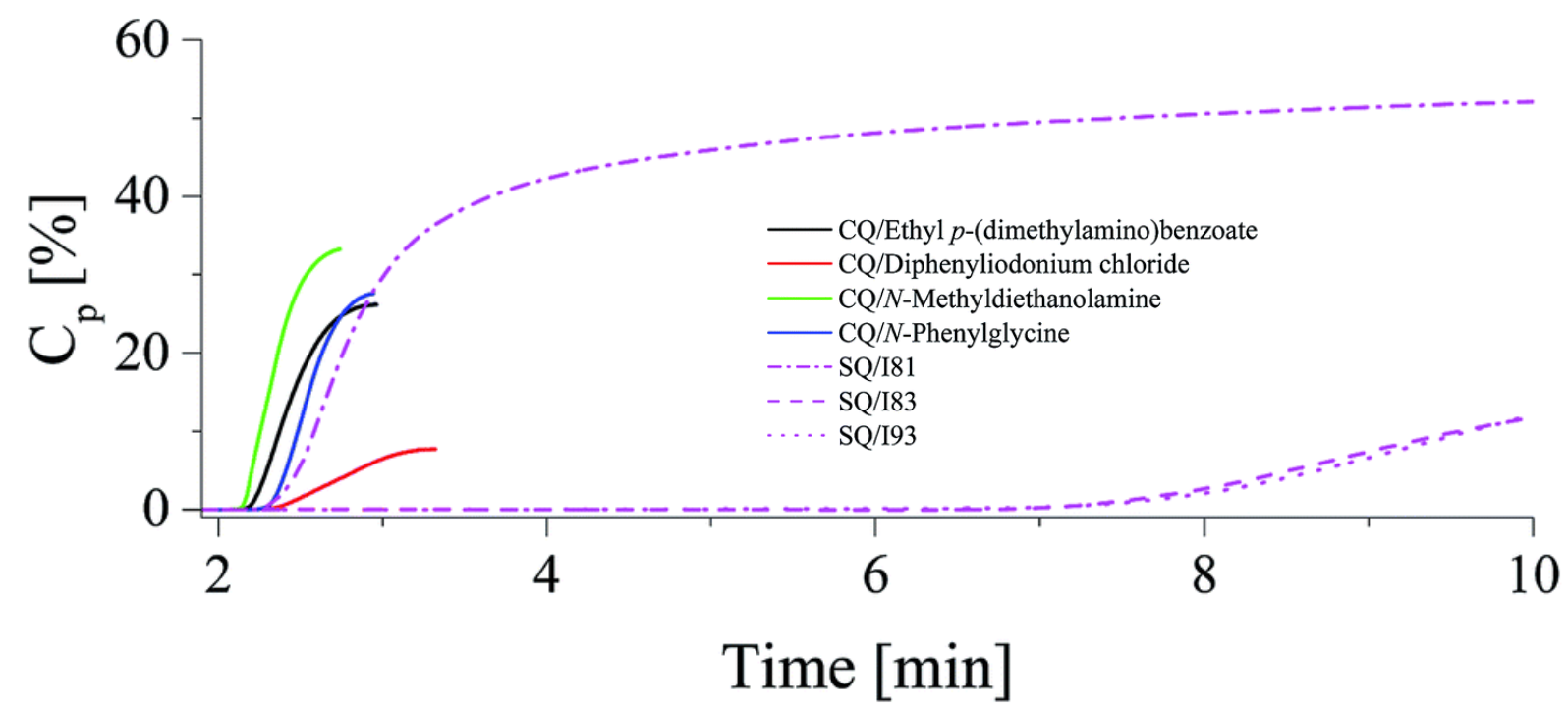

Figure 12. Polymerization profiles of TMPTA using the two-component SQ2/I81 system and comparisons with the reference photoinitiating systems. Reproduced with permission of Ref. [205].

In line of the previous study, influence of the substitution pattern of a series of $N$ alkoxypyridinium salts used as co-initiators was carried out, still while using SQ2 as the photosensitizer (See Figure 13).[206]

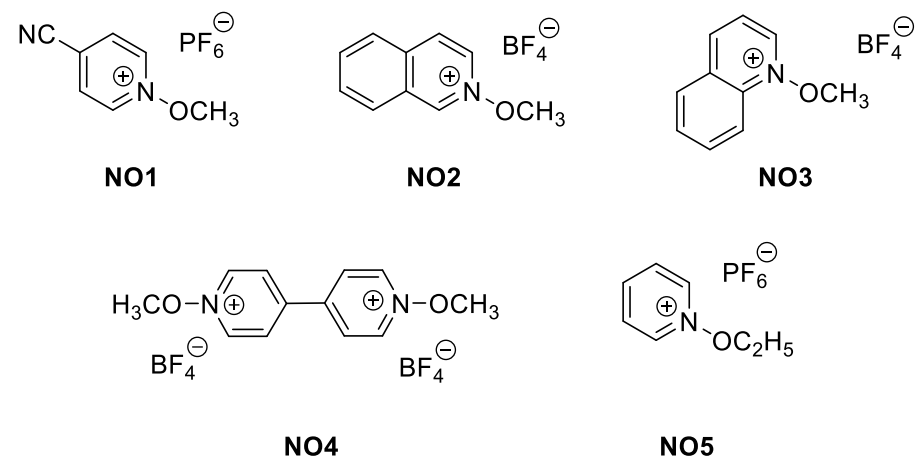

Figure 13. Chemical structures of $\mathrm{N}$-alkoxypyridinium salts NO1-NO5 used as co-initiators with SQ2.

With this series of six different $\mathrm{N}$-alkoxypyridinium salts (NO-NO5), photoinitiating abilities of the two-component systems was determined to be independent of the rate constant of fragmentation of the pyridyl radicals. Indeed, if the fragmentation of the radicals issued from the $\mathrm{N}$-methoxy-4-cyanopyridinium cations (NO1) was determined as occurring six times faster than that observed for the $N, N^{\prime}$-dimethoxy-4,4'-dipyridylium dications (NO4), these 
results were in contradiction to the TMPTA conversions determined with the two twocomponent systems. Indeed, final monomer conversion of 35 and $54 \%$ were respectively determined with the two-component SQ2/NO1 and SQ2/NO4 systems after 10 minutes of irradiation with visible light. In fact, monomer conversions higher than $50 \%$ could be determined with NO, NO2-NO4. Electronic delocalization and resonance stabilization of the pyridyl radicals were determined as the main factors governing the polymerization efficiency. Indeed, for NO1 and NO5 for which the $\mathrm{N}$-alkoxypyridinium salts do not exhibit and an additional aromatic ring, low TMPTA conversions of 35 and $25 \%$ were respectively determined with the two-component SQ2/NO2 and SQ2/NO5 systems. Here again, comparisons with reference photoinitiating systems based on camphorquinone (CQ) revealed the examined systems to be less efficient than the two-component CQ/MDEA or CQ/NPG systems (where MDEA and NPG respectively stand for $\mathrm{N}$-methyldiethanolamine and $\mathrm{N}$ phenylglycine respectively). Even Type I photoinitiator such as bis-acylphosphine oxide (BAPO) could outperform the best SQ/ N-alkoxypyridinium system (See Figure 14).

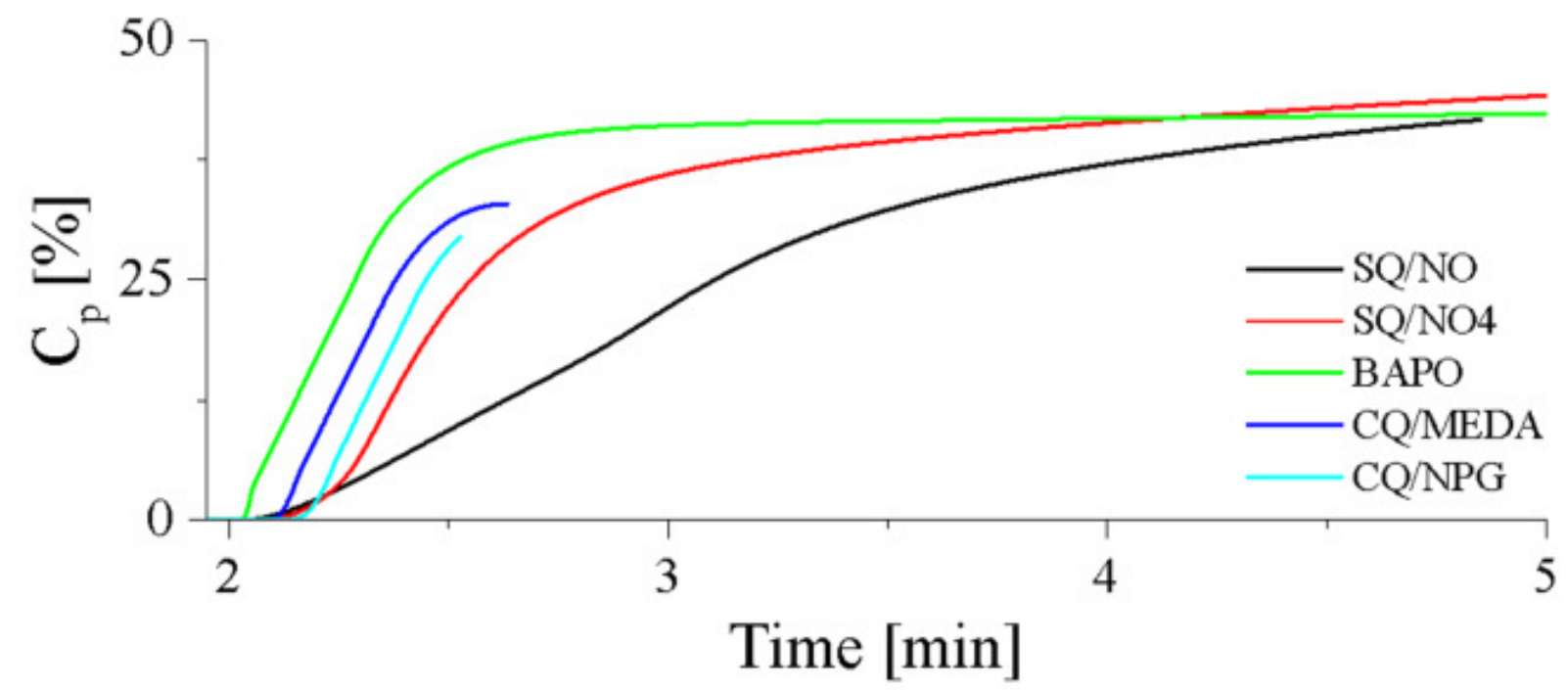

Figure 14. Comparisons between $\mathrm{SQ} / \mathrm{NO}$ systems and reference photoinitiating systems for the visible light polymerization of TMPTA. Reproduced with permission from Ref. [206]

In 2017, the same group examined this time the influence of the substitution pattern of a series of 1,3-bis( $p$-substituted phenylamino)squaraines SQ2, SQG1-SQG5, SQG7-SQG9 on the photoinitiating abilities (See Figure 15).[207] Among the most interesting findings, the highest TMPTA conversions were obtained with SQG8, exhibiting a sulfonic group. By using Iod4 and $\mathrm{B}$ as the co-initiators, final monomer conversions of $41 \%$ and $27 \%$ could be obtained after 15 minutes of visible light irradiation. Good monomer conversions could also be determined for all squaraines bearing halogens such as SQ2, SQG5 and SQG7. However, while using NO as the coinitiator, the order of reactivity changed and the highest monomer conversions were obtained with SQ2, SQ3 and SQ4. In this case, monomer conversions of 68,50 and $48 \%$ were determined during the FRP of TMPTA using the two-component SQ4/NO, SQ2/NO and SQ3/NO systems. Interestingly, if an induction time around 8 minutes could be observed for numerous photoinitiating systems based on B and Iod4, conversely, no inhibition time was 
observed with NO. It was thus concluded that the fragmentation of $\mathrm{N}$-alkoxypyridinyl radicals was furnishing more reactive radicals than phenyl or alkyl radicals formed by decomposition of Iod4 and B. Comparisons with benchmark Type I photoinitiators revealed that only the SQG4/NO and SQG2/NO combinations could outperform diphenyl(2,4,6trimethylbenzoyl)phosphine oxide (TPO) or BAPO.
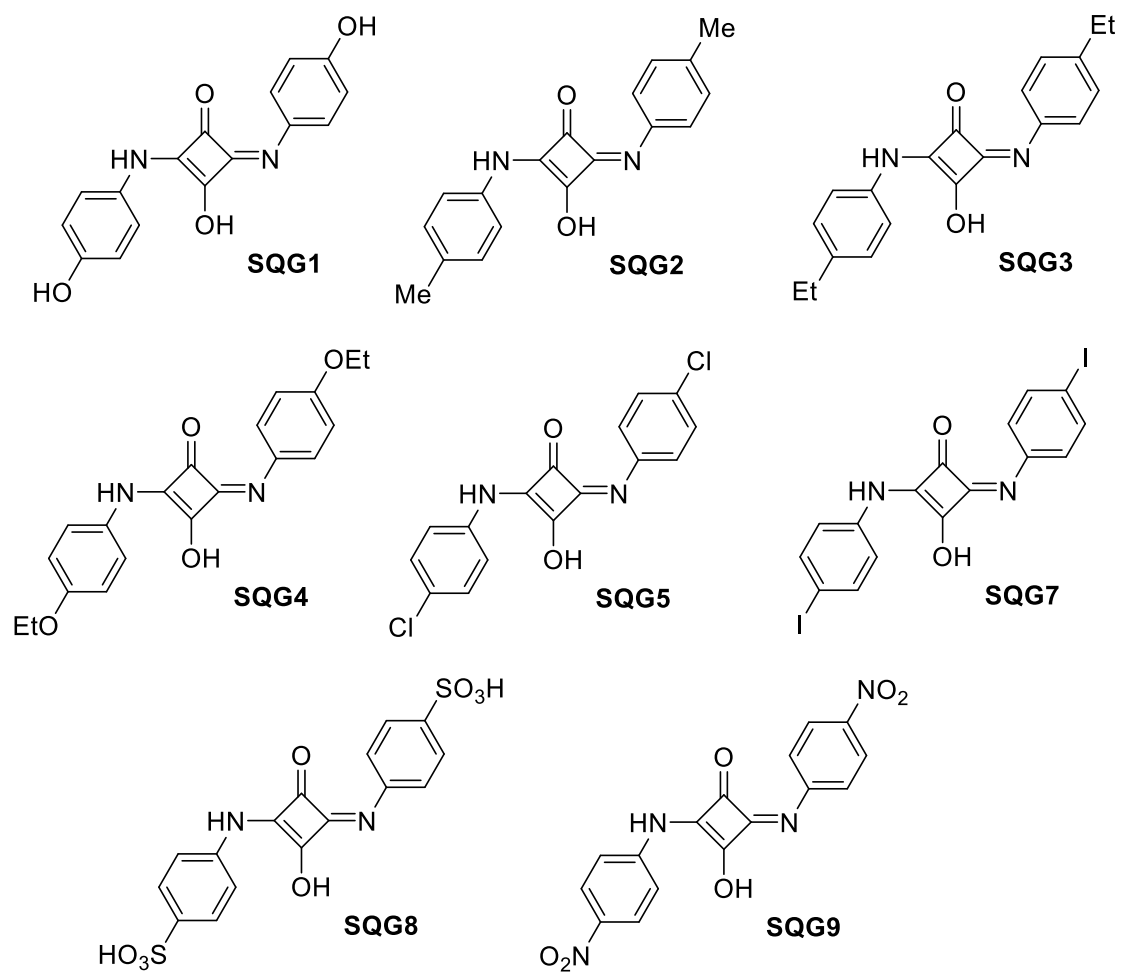

Figure 15. Chemical structures of 1,3-bis( $p$-substituted phenylamino)squaraines SQG1-SQG5, SQG7-SQG9.

With aim at improving the monomer conversion, the same group examined in 2020 the possibility to develop three-component systems with squaraines.[208] Various combinations of co-initiators (Iod1, Iod4, I77, I81, N-vinylcarbazole (NVK), B and tris(trimethylsilyl)silane (TTMSS) were tested with SQ1 used as the photosensitizer (See Figure 16).

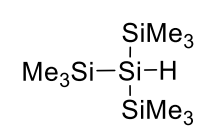

TTMSS

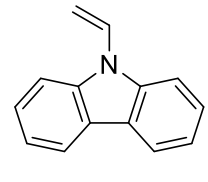

NVK

Figure 16. Chemical structures of TTMSS and NVK used as additives for SQ1 and used to prepare three-component photoinitiating systems.

In this work, the authors focused on a silane derivative i.e. tris(trimethylsilyl)silane (TTMSS) as silanes are classical additives for photopolymerization.[209-211] Notably, silanes are well-known to reduce oxygen inhibition by acting as peroxide scavengers.[212-217] By reacting with oxygen, silanes are capable to convert unreactive peroxyls radicals $\mathrm{ROO} \bullet$ as reactive $\mathrm{R}_{3} \mathrm{Si} \bullet$ according to the mechanism depicted in the Figure 17. Using this strategy, the 
concentration of reactive $\mathrm{R}_{3} \mathrm{Si} \bullet$ radicals can be maintained sufficiently high even in the presence of oxygen so that the polymerization process can proceed.

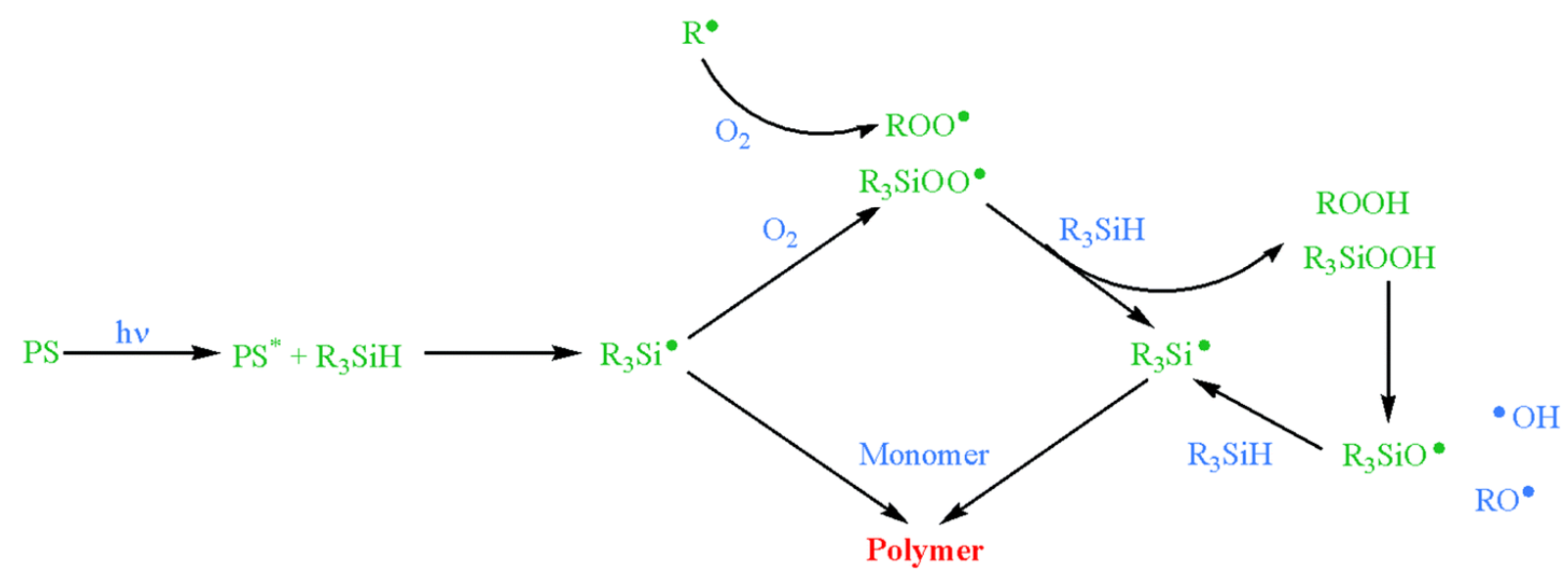

Figure 17. Mechanism enabling to reduce oxygen inhibition using silane as an oxygen scavenger. Reproduced with permission of Ref. [208]

Among the tested three-component systems, the highest TMPTA conversion was obtained with TTMSS and (4-methoxyphenyl)-(4-nitrophenyl)iodonium $p$-toluenesulfonate (I81) as the additives. Monitoring of the reaction process by photoassisted differential scanning calorimetry (photo-DSC) revealed the heat released by the three-component system SQ1/I81/TTMSS to be 10 times higher than that released by the other photoinitiating systems (SQ1/TTMSS/B, SQ1/TTMSS/NVK, SQ1/TTMSS/Iod1, SQ1/TTMSS/Iod4, SQ1/TTMSS/I77 and SQ1/TTMSS/I81). Thus, if the TMPTA conversion reached $58 \%$ with the three-component system SQ1/TTMSS/I81/ $\left(1 \times 10^{-3} \mathrm{M} / 5 \times 10^{-3} \mathrm{M} / 2 \times 10^{-3} \mathrm{M}\right)$ upon irradiation with a visible light for 12 minutes, the monomer conversions rapidly decreased to 36 and $24 \%$ for the three-component systems SQ1/TTMSS/I1 and SQ1/TTMSS/I77 $\left(1 \times 10^{-3} \mathrm{M} / 5 \times 10^{-3} \mathrm{M} / 2 \times 10^{-3} \mathrm{M}\right)$ in the same conditions. Influence of the counter-anions on the photoinitiating efficiency was clearly evidenced while comparing Iod1 and Iod4. Indeed, a two-fold enhancement of the monomer conversion could be obtained for the three-component system SQ1/TTMSS/Iod4 compared to the SQ1/TTMSS/Iod1 system (36\% vs. $18 \%$ for the second system). Conversely, the threecomponent system SQ1/TTMSS/B $\left(1 \times 10^{-3} \mathrm{M} / 5 \times 10^{-3} \mathrm{M} / 2 \times 10^{-3} \mathrm{M}\right)$ only gave a moderate monomer conversion, peaking at $20 \%$ for TMPTA. Finally, the same year, Kabatc and coworkers revisited the three-component photoinitiating systems based on SQ1 as the photosensitizer with a new series of iodonium salts varying from the former ones by the substitution pattern.[218] Notably, a wide range of meta-substituted iodonium salts were tested as additives for SQ1 and B (See Figure 18). Using the three component-systems SQ1/I81m/B, $\mathrm{SQ} / \mathrm{I} 84 \mathrm{~m} / \mathrm{B}$ and SQ1/193m/B, TMPTA conversions of 50,52 and $55 \%$ yields were respectively obtained upon irradiation with a visible light $\left(30 \mathrm{~mW} / \mathrm{cm}^{2}\right)$ for 10 minutes. For comparison, a monomer conversion of $44 \%$ could be determined with the three component-systems SQ1/Iod4/B, demonstrating that the presence of electron withdrawing group at the metaposition of iodine could improve the reactivity of the iodonium salt. Indeed, due to the presence of electron-withdrawing groups, aryl radicals formed by the photoassisted fragmentation of the iodonium salts are stabilized by electron delocalization. 


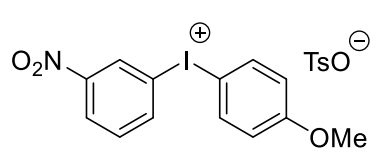

$181 \mathrm{~m}$

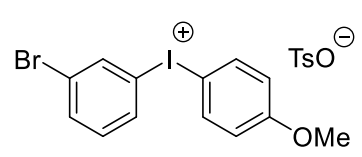

$184 \mathrm{~m}$

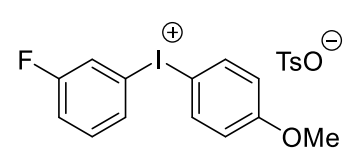

$193 m$

Figure 18. Chemical structure of meta-substituted iodonium salts $181 \mathrm{~m}, \mathrm{I} 84 \mathrm{~m}$ and $\mathrm{I} 93 \mathrm{~m}$ used as additives for SQ1.

Finally, comparisons with reference compounds revealed that the three-component systems based on $181 \mathrm{~m}$, I84m and $193 \mathrm{~m}$ could outperform benchmark photoinitiating systems based on camphorquinone as the photosensitizer. (See Figure 19).

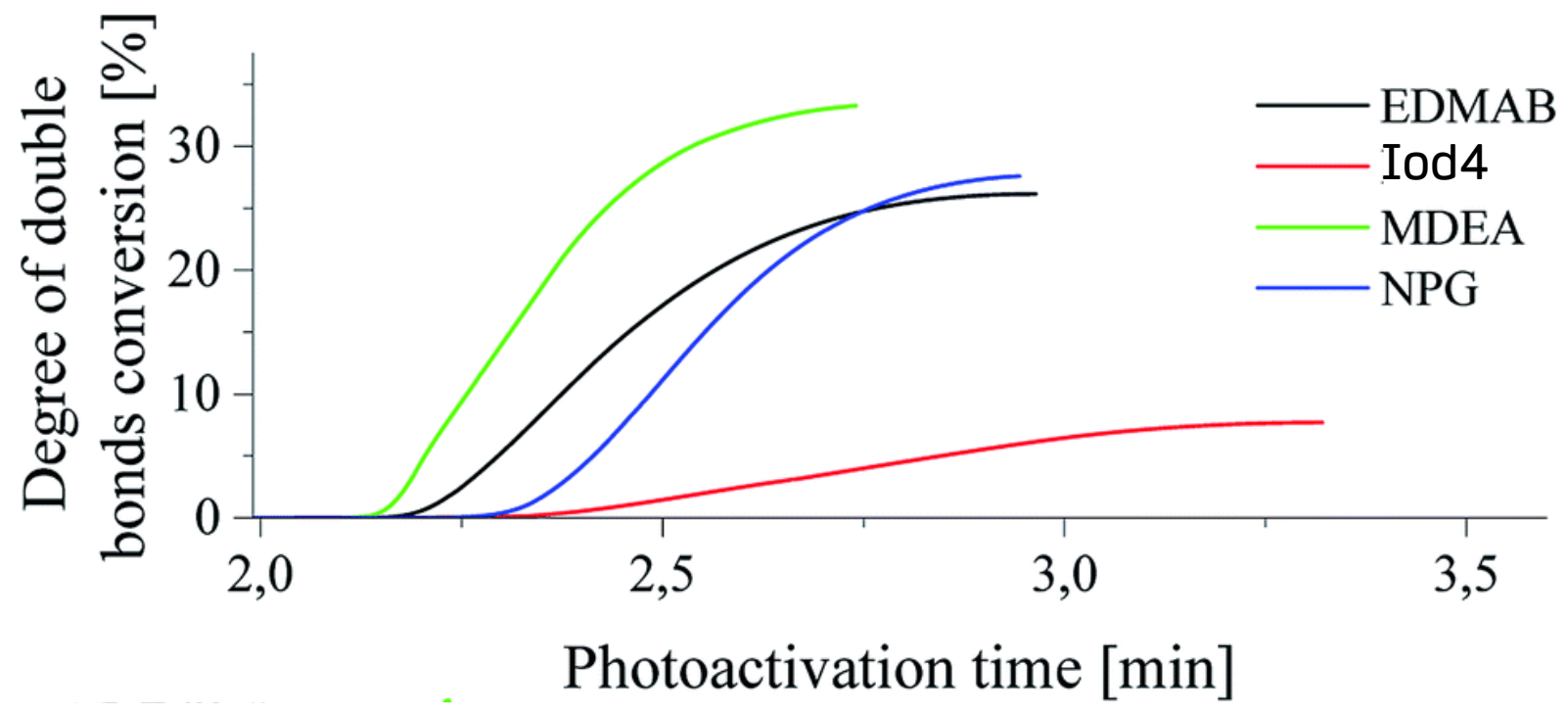

Figure 19. TMPTA conversions obtained with reference systems in the same conditions than that used for the three-component SQ/Iodonium/B systems. Reference system : CQ/ethyl p( $N, N$-dimethylamino)benzoate (EDMAB), CQ/ Iod4, CQ/MDEA, CQ/NPG upon irradiation with a visible light in the $300 \mathrm{~nm}-500 \mathrm{~nm}$ range. Reproduced with permission of Ref. [218]

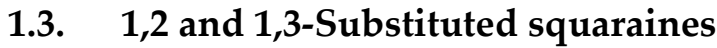

Organic electronics is an unlimited source of dyes that can be advantageously used for the design of photoinitiators of polymerization.[146] Indeed, to be usable in electronic systems, organic compounds should exhibit high molar extinction coefficients (notably for energy conversion applications), but also reversible electrochemical properties. Indeed, the working principle of a solar cell or an organic light-emitting diode typically involves the active materials to be oxidized or reduced during device operation, depending on the Fermi levels of the two electrodes used for the device stacking. In 2013, a squaraine classically used for the design of organic solar cells, namely 5-carboxy-2-[[3-[(2,3-dihydro-1,1-dimethyl-3-ethyl-1Hbenzo[e]indol-2-ylidene)methyl]-2-hydroxy-4-oxo-2-cyclobuten-1-ylidene]methyl]-3,3-

dimethyl-1-octyl-3H-indolium (SQ02) [219-220] was examined as a photosensitizer for the FRP of acrylates and the cationic polymerization (CP) of epoxides (See Figure 20).[221] Among squaraines, SQ02 was the first squaraine to be tested as a photosensitizer for the $\mathrm{CP}$ of epoxides, irrespective of the irradiation conditions. In this work, the authors focused their work on visible light polymerization using a Laser diode emitting at $635 \mathrm{~nm}\left(\mathrm{I}=100 \mathrm{~mW} / \mathrm{cm}^{2}\right)$. 
As classically observed for squaraines, the absorption spectrum of SQ02 was relatively narrow, ranging between 500 and $700 \mathrm{~nm}$, with an absorption maximum located at $653 \mathrm{~nm}$ in acetonitrile. An exceptional molar extinction coefficient could also be determined for this dye, peaking at $221100 \mathrm{M}^{-1} \cdot \mathrm{cm}^{-1}$.

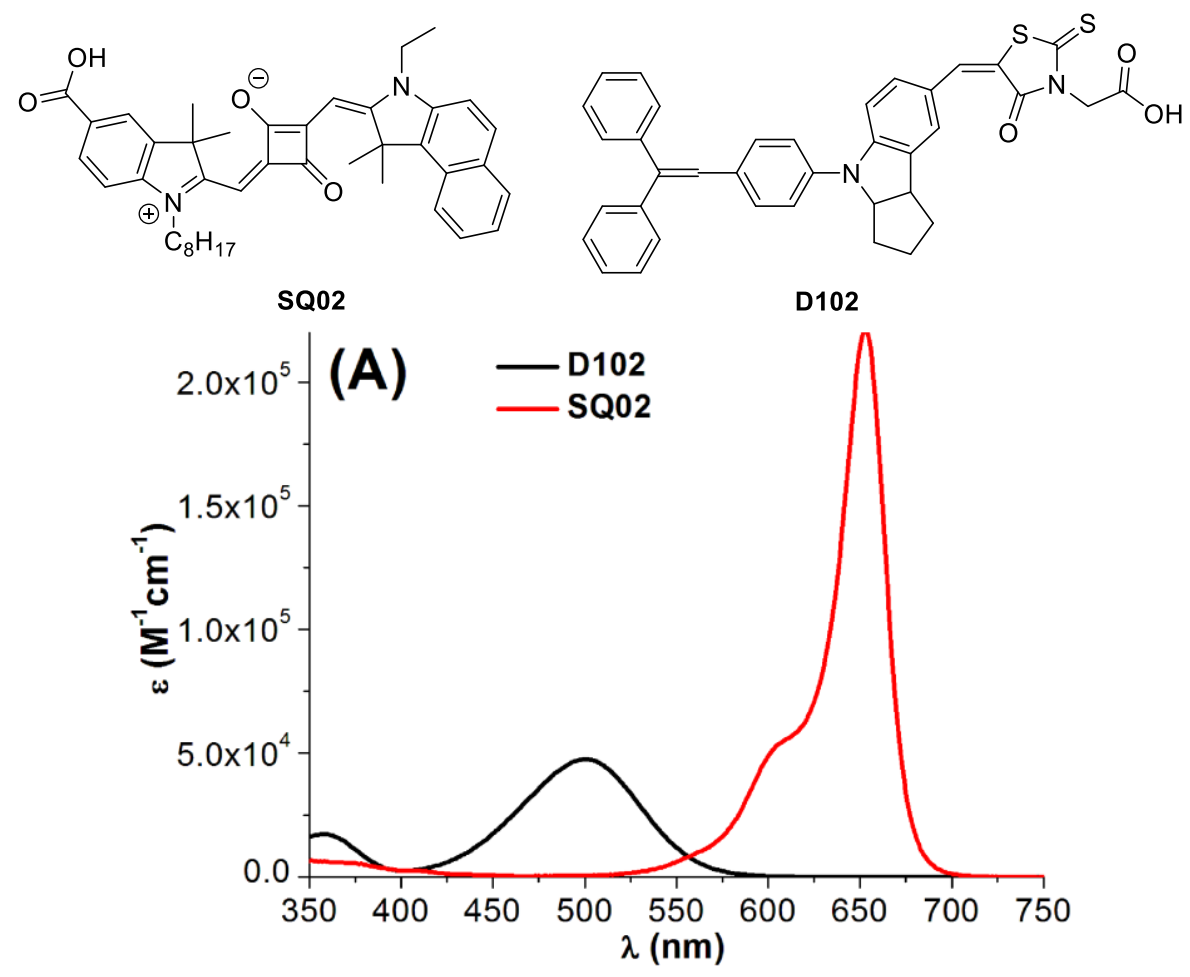

Figure 20. Chemical structure of SQ02 and UV-visible absorption spectra of SQ02 and D102 in acetonitrile. Reproduced with permission of Ref. [221].

Photopolymerization tests done with EPOX and tri(ethylene glycol)divinyl ether (DVE-3) revealed the two-component system SQ02/Iod1 $(0.5 \% / 2 \%, w / w)$ to only furnish moderate monomer conversions compared to the three-component system SQ02/Iod1/NVK $(0.5 \% / 2 \% / 3 \%, w / w / w)$ upon irradiation with a halogen lamp (29 vs $37 \%$ conversion). Surprisingly, while irradiating in the absorption maximum of SQ02 i.e. at $635 \mathrm{~nm}$, a decrease of the monomer conversion was found, peaking at $24 \%$ and this counter-performance was assigned to inter filter effects, the absorption of SQ02 being maximum in the 600-700 $\mathrm{nm}$ range. Here again, the crucial role of NVK and TTMSS to improve the monomer conversions was demonstrated, by comparing the final monomer conversions obtained for the threecomponent SQ02/Iod1/NVK $(0.5 \% / 2 \% / 3 \%, w / w / w)$ and the four-component system SQ02/Iod1/NVK/TTMSS $(0.5 \% / 2 \% / 3 \% / 3 \%, w / w / w / w)$. However, if an enhancement was detected, it remained however moderate, the difference being only of $3 \%$ additional monomer conversion (37\% vs $40 \%$ final monomer conversions). While examining the CP of DVE-3 in laminate, high monomer conversions could be obtained with the two-component system SQ02/Iod1 $(0.5 \% / 2 \%, \mathrm{w} / \mathrm{w})$, both upon irradiation with a halogen lamp and at $535 \mathrm{~nm}$ (90 and $87 \%$ conversions respectively). Interestingly, panchromatic photoinitiating systems could be developed by using the complementarity of the absorption of SQ02 with an indoline dye i.e. 2-(5-((4-(4-(2,2-diphenylvinyl)phenyl)-1,2,3,3a,4,8b-hexahydrocyclopenta[b]indol-7-yl) 
methylene)-4-oxo-2-thioxothiazolidin-3-yl)acetic acid (D102) (See Figure 20). By using the four-component SQ02/D102/Iod/NVK system, high final monomer conversions could be obtained during the $\mathrm{CP}$ of DVE-3 upon irradiation with Laser diodes of emissions ranging from 457 to 473,532 and $635 \mathrm{~nm}$, or by using a polychromatic halogen lamp.

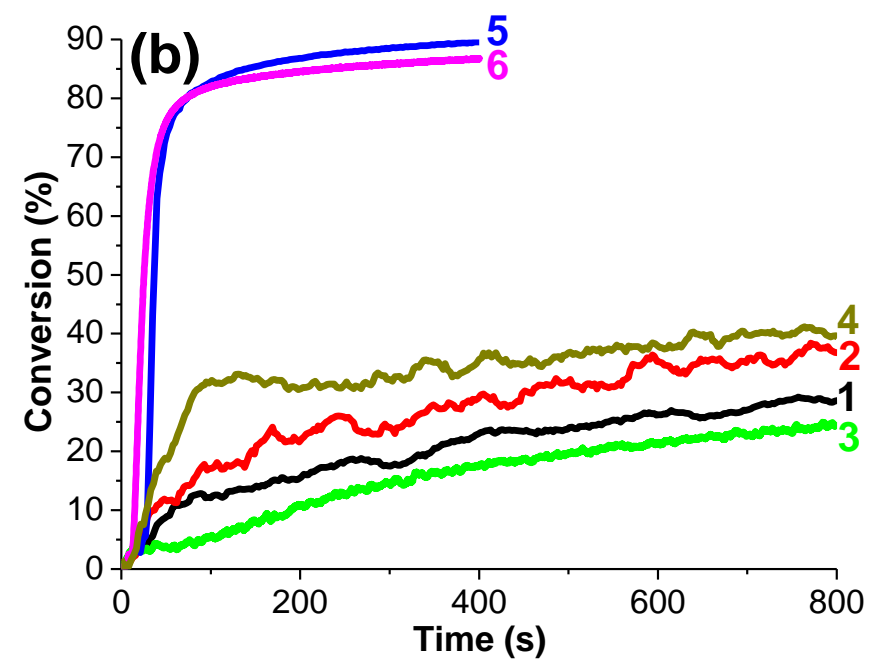

Figure 22. (i) Polymerization profiles of EPOX under air monitored by FTIR using : (1) SQ02/Iod1 (0.5\%/2\%, w/w), halogen lamp; (2) SQ02/Iod1/NVK (0.5\%/2\%/3\%, w/w/w), halogen lamp; (3) SQ02/Iod1/NVK $(0.5 \% / 2 \% / 3 \%, w / w / w)$, laser diode at $635 \mathrm{~nm}$; (4) SQ02/Iod1/NVK/TTMSS $(0.5 \% / 2 \% / 3 \% / 3 \%, \mathrm{w} / \mathrm{w} / \mathrm{w} / \mathrm{w})$, halogen lamp; (ii) Polymerization profiles of DVE-3 in laminate monitored by FTIR using SQ02/Iod1 (0.5\%/2\%, w/w) (5) halogen lamp and (6) laser diode at $635 \mathrm{~nm}$. Reproduced with permission of Ref. [221]

SQ02-based photoinitiating systems could also efficiently initiate the FRP of TMPTA in laminate and under soft irradiation conditions. While using the two-component system SQ02/Iod1 $(0.5 \% / 2 \%, w / w)$ or the three-component system SQ02/Iod1/NVK $(0.5 \% / 2 \% / 3 \%$, $\mathrm{w} / \mathrm{w} / \mathrm{w}$ ) upon irradiation with a halogen lamp or a laser diode at $635 \mathrm{~nm}$, monomer conversions ranging between 38 and 40 could be determined after $800 \mathrm{~s}$ of irradiation. Noticeably, no significant improvement of the monomer conversion was detected with the three-component system. Besides, in the presence of NVK, highly reactive Ph-NVK • radicals are formed, that should improve the polymerization efficiency. On the basis of the photolysis experiments, the following mechanism was proposed by the authors.

$$
\begin{aligned}
& \text { Dye } \rightarrow{ }^{1} \text { Dye }(\mathrm{h} v) \text { and }{ }^{1} \text { Dye } \rightarrow{ }^{3} \text { Dye } \\
& { }^{1,3} \text { Dye }+\mathrm{Ph}_{2} \mathrm{I}^{+} \rightarrow \mathrm{Dye}^{\bullet+}+\mathrm{Ph}_{2} I^{\bullet} \rightarrow \mathrm{Dye}^{\bullet+}+\mathrm{Ph} \bullet+\mathrm{Ph}-\mathrm{I} \\
& \mathrm{Ph}+\mathrm{NVK} \rightarrow \mathrm{Ph}-\mathrm{NVK} \bullet \\
& \mathrm{Ph}-\mathrm{NVK} \bullet+\mathrm{Ph}_{2} \mathrm{I}^{+} \rightarrow \mathrm{Ph}-\mathrm{NVK}^{+}+\mathrm{Ph} \bullet+\mathrm{Ph}-\mathrm{I}
\end{aligned}
$$

Squaraines are also well-known to strongly absorb in the near infrared region so that polymerization tests were carried out at these long wavelengths. Indeed, one of the advantages of near-infrared photopolymerization is the possibility to get a high light penetration within 
the resins, enabling the access to thick samples. In 2019, a series of 1,2 and 1,3-substituted squaraines were investigated as photosensitizers for the FRP of acrylates at $785 \mathrm{~nm}, 940 \mathrm{~nm}$ and $1064 \mathrm{~nm}$.[61] If cyanines have been extensively studied for the design of near infrared photoinitiating systems, 1,2 and 1,3-substituted squaraines have never been tested prior to this work.[59,222-236] NIR dyes are also well-known to release heat upon photoexcitation, and this property is at the basis of numerous photothermal cancer therapies.[237-242] In the context of photopolymerization, if sufficient heat is released during photoexcitation of the NIR dyes, decomposition of a thermal initiator can be initiated, inducing a photoassisted thermal polymerization process. In this case, the NIR dyes is used as a heater.[223] Parallel to this, if the NIR dye is combined with the appropriate additives, radicals can also be photochemically generated, as classically observed during photopolymerization. As a result of the concomitant photochemical and photothermal polymerization processes, high concentrations of initiating species can be obtained, boosting the polymerization process and improving the monomer conversion. This dual strategy was notably applied with a series of 1,2 and 1,3-substituted squaraines (SQ_1-SQ_4, SQm_1-SQm_4) whose chemical structures is presented in the Figure 22. As the main finding of this work, almost no polymerization was observed while using the photochemical process alone or the photothermal process alone, demonstrating that the two sources of radicals were required to get an acceptable monomer conversion. Even if the different dyes exhibit low molar extinction coefficients at 785, 940 and $1064 \mathrm{~nm}$, the absorptions remained sufficient to initiate a polymerization process (See Figure 23). For this study, 2-methyl-2-[N-tert-butyl-N-(1-diethoxyphosphoryl-2,2- dimethylpropyl) aminoxy]propionic acid (Blocbuilder MA) was selected as the thermal initiator whereas a phosphine, namely, 4-(diphenylphosphino)benzoic acid (4-dppba) was used as an additive. In fact, a thermosensitive alkoxyamine i.e. Blockbuilder®MA was selected for its low decomposition temperature, around $70^{\circ} \mathrm{C}$.[243-245] As shown in the Figure 24, the four fourcomponent systems could efficiently initiate the FRP of a mixture of acrylate (Mix-MA) upon irradiation at $785 \mathrm{~nm}\left(\mathrm{I}=400 \mathrm{~mW} / \mathrm{cm}^{2}\right)$ and $940 \mathrm{~nm}\left(\mathrm{I}=4 \mathrm{~W} / \mathrm{cm}^{2}\right)$. Final conversion higher than $75 \%$ could be determined with all photoinitiating systems, irrespective of the irradiation wavelength. Best results were obtained with SQ_3 and SQ_4. While examining the photoinitiating ability of 1,3-susbtituted squaraines, no polymerization could be initiated with SQm_2 at $940 \mathrm{~nm}$ and only low monomer conversions were obtained with SQm_1 and SQm_3 due to their low molar extinction coefficient at these wavelengths. Besides, if a low monomer conversion was obtained with SQm_3 a at 785 nm ( 30 \% final monomer conversion after 500 s of irradiation). Conversely, a monomer conversion reaching $60 \%$ was obtained with SQm_3. This counter-intuitive result has to be directly related to the respective irradiance of the two lamps: $400 \mathrm{~mW} / \mathrm{cm}^{2}$ at $785 \mathrm{~nm}$ vs $3 \mathrm{~W} / \mathrm{cm}^{2}$ at $940 \mathrm{~nm}$. Therefore, despites the lower molar extinction coefficient of SQm_3 at $940 \mathrm{~nm}$, a higher monomer conversion could be obtained at $940 \mathrm{~nm}$ than $785 \mathrm{~nm}$ thanks to the higher light intensity (See Figure 25). 


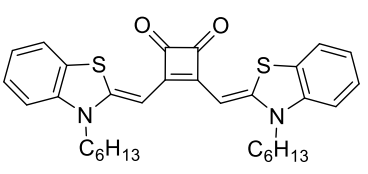

SQ_1

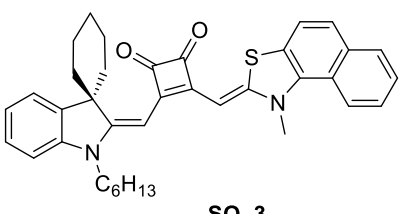

SQ_3

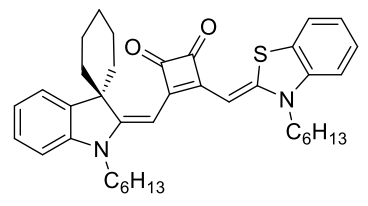

SQ_2

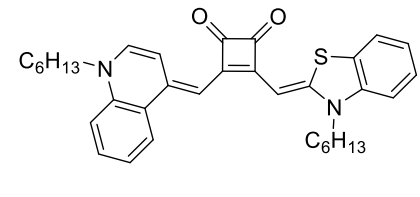

SQ_4
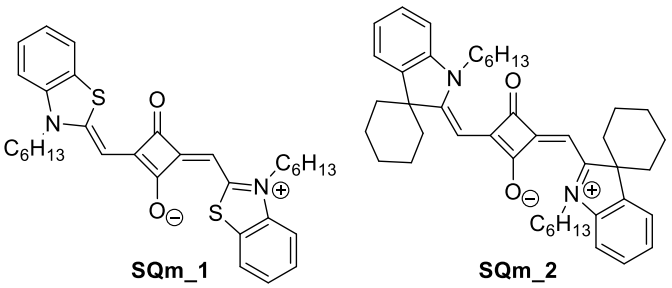

SQm_2
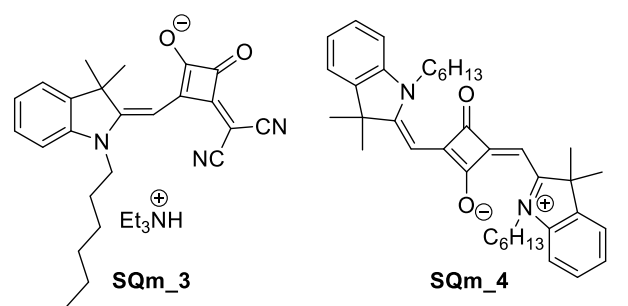

Co-initiators

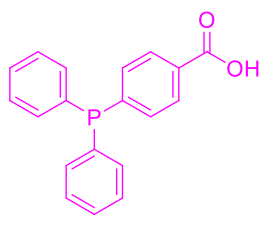

4-dppba

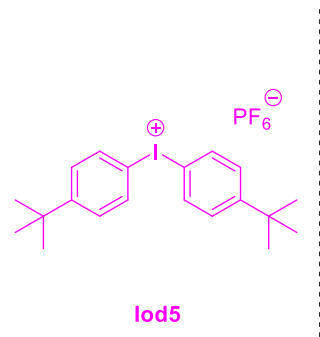

$\operatorname{lod} 5$
Thermal initiator

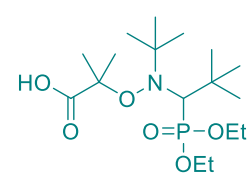

BlocBuilder MA
Monomers
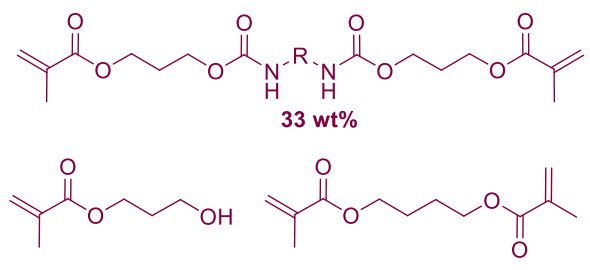

HPMA $33 w t \% \quad 1,4-B D D M A 33 w t \%$

Figure 22. Chemical structures of 1,2 and 1,3-substituted squaraines, monomers and additives used for a dual photochemical and photothermal polymerization process.
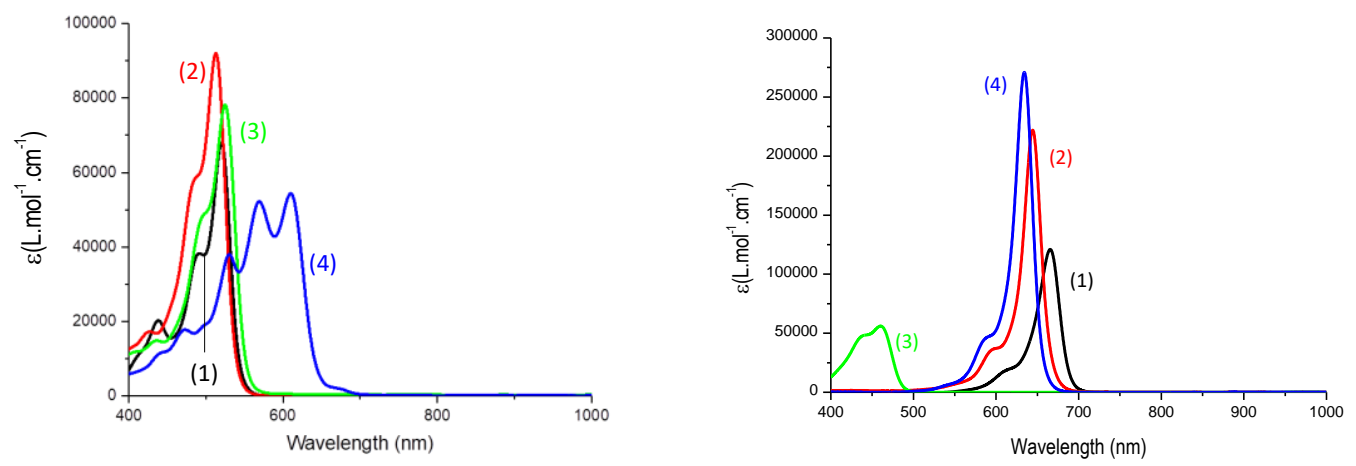

Figure 23. UV-visible absorption spectra of SQ_1-SQ_4, SQm_1-SQm_4 in acetonitrile. Reproduced with permission of Ref. [61] 

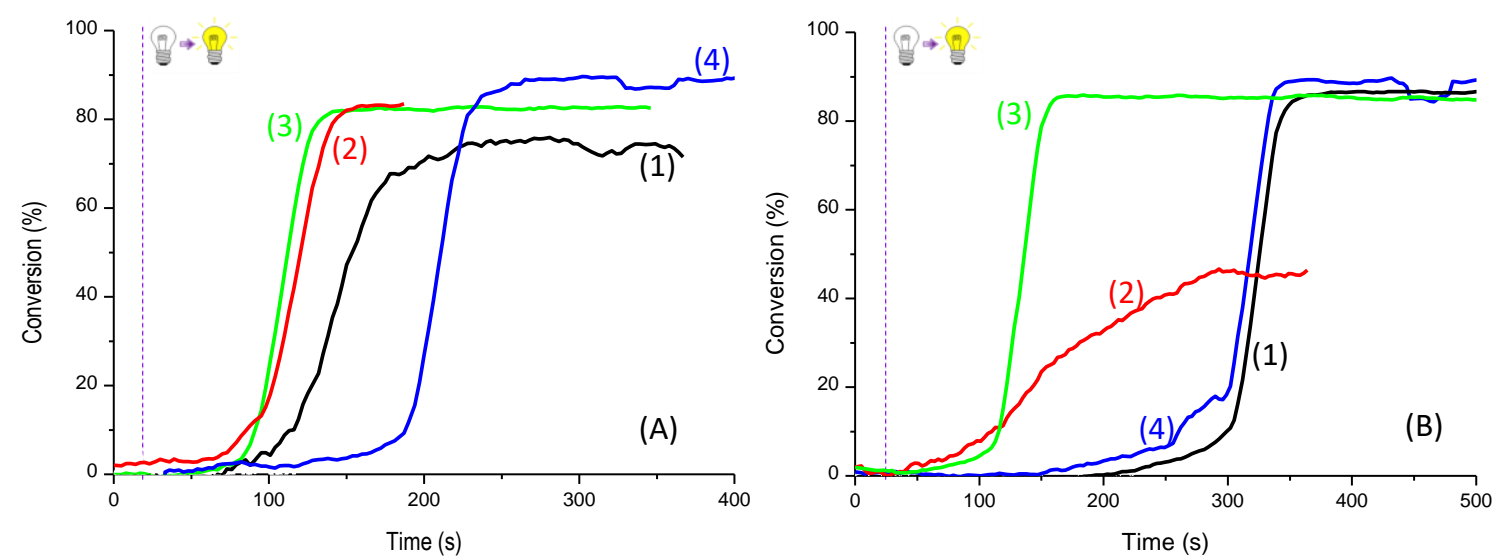

Figure 24. Photopolymerization profiles of Mix-MA under air using Iod5 (3 w\%), 4-dppba (2 w\%), BlocBuilder®MA (2 w\%) and: (1) SQ_1 (0.1 w\%), (2) SQ_2 (0.1 w\%), (3) SQ_3 (0.1 w\%), (4) SQ_4 (0.1 w\%) upon irradiation with (A) Laser Diode@785nm (B) Laser Diode@940nm. Reproduced with permission of Ref. [61]
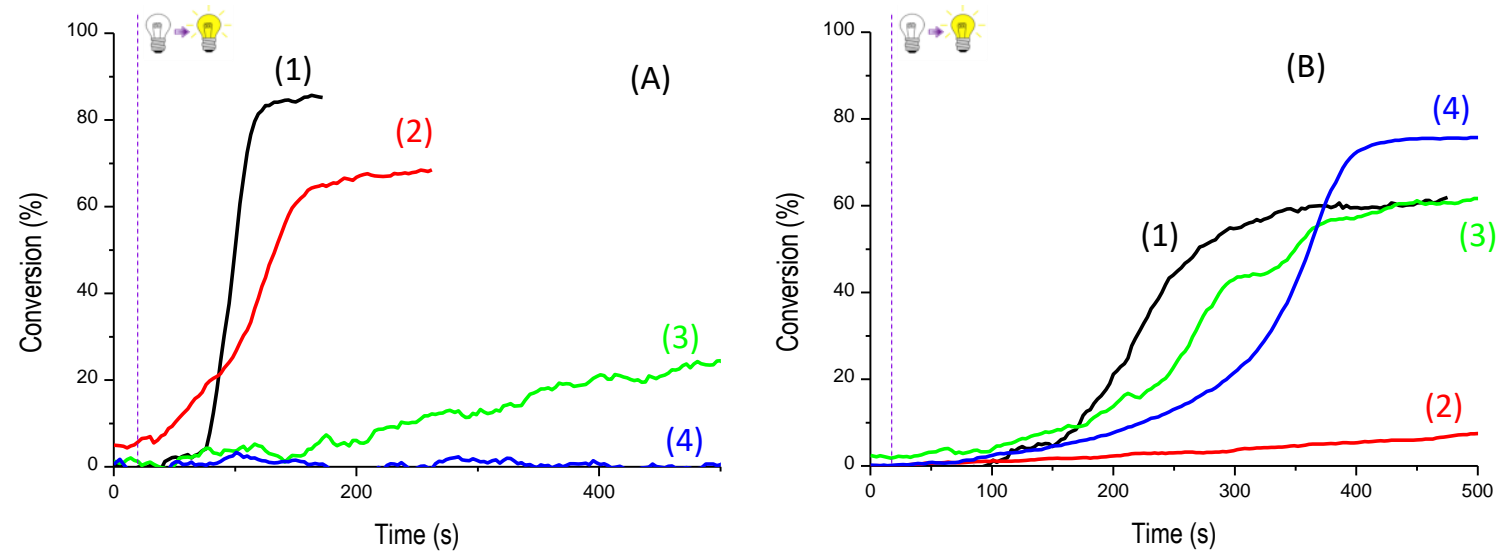

Figure 25. Photopolymerization profiles of Mix-MA under air using Iod5 (3 w\%), 4-dppba (2 w\%), BlocBuilder®MA (2 w\%) and: (1) SQm _1 (0.1 w\%), (2) SQm_2 (0.1 w\%), (3) SQm_3 (0.1 w\%), (4) SQm_4 (0.1 w\%) upon irradiation (A) Laser Diode@785 nm (B) Laser Diode@940 nm. Reproduced with permission of Ref. [61]

Finally, in 2021, a squaraine was used as an innovative tool for plastics recycling and reprocessing upon near-infrared photoactivation (See Figure 26).[60] Indeed, one efficient strategy to improve the lifetime of plastics consists in the recovering of plastics and to proceed to plastic reprocessing or recycling. To support this approach, in 2018, only $32.5 \%$ of the plastic wastes were recycled whereas $25 \%$ were simply landfilled without giving a new valorisation to these plastics.[246-248] To improve the polymer lifetime, healing of cracks constitutes an appealing approach, but requires high temperature to be reached. This strategy which constitutes an environmentally friendly approach to give a second life to polymers can be achieved with NIR dyes, for which an efficient light-to heat conversion can be obtained. In the work done by the group of Lalevée and coworkers, a NIR dye SQ03 was introduced into a 
polymer for self-healing applications. However, in this work, the NIR dye was not used as a photosensitizer since the photopolymerization of the glyfoma resin was achieved while using a benchmark UV photoinitiator, namely phenyl bis(2,4,6-trimethylbenzoyl)phosphine oxide (SPBPO). The NIR dye was simply mixed into the photocurable resin in order to be prepositioned for plastic reprocessing. To give a proof of concept, a polymer exhibiting a low glass-transition temperature was selected, based on a glyfoma resin. Indeed, in order to reprocess polymers, a temperature higher than the glass transition temperature has to be reached by the NIR dye.

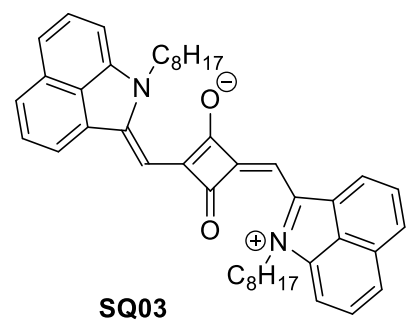

Figure 26. Squaraine dye SQ03 used for plastics recycling and reprocessing.

Experiments of heat release were carried out in another polymer, namely a TMPTAbased polymer also polymerized with phenyl bis(2,4,6-trimethylbenzoyl)phosphine oxide (SPBPO) $(1 \mathrm{wt} \%)$ and containing SQ03 with concentration ranging from 0 to $2 \mathrm{wt} \%$. As shown in the Table 2, depending on the irradiation wavelength, the temperature raised by the polymers could increase up to $260^{\circ} \mathrm{C}$ upon excitation at $980 \mathrm{~nm}$. An increase of the polymer temperature could also be observed while increasing the dye content into the polymer and a linear correlation between dye concentration and polymer temperature could even be established.

Table 2. Maximal temperature reached for the TMPTA-based polymer containing SQ03 (0.05 \%wt) upon irradiation with NIR lights: $785 \mathrm{~nm}\left(2.55\right.$ W.cm $\left.{ }^{-2}\right), 850 \mathrm{~nm}\left(1 \mathrm{~W} . \mathrm{cm}^{-2}\right), 940 \mathrm{~nm}(2.16$ W.cm $\left.{ }^{-2}\right), 980 \mathrm{~nm}\left(3.12\right.$ W.cm $\left.{ }^{-2}\right), 1064 \mathrm{~nm}(3.12$ W.cm-2).

\begin{tabular}{|l|l|l|}
\hline & Without heater & Heater SQ03 \\
\hline $785 \mathrm{~nm}$ & $40^{\circ} \mathrm{C}$ & $143^{\circ} \mathrm{C}$ \\
\hline $850 \mathrm{~nm}$ & $38^{\circ} \mathrm{C}$ & $97^{\circ} \mathrm{C}$ \\
\hline $940 \mathrm{~nm}$ & $28^{\circ} \mathrm{C}$ & $174^{\circ} \mathrm{C}$ \\
\hline $980 \mathrm{~nm}$ & $27^{\circ} \mathrm{C}$ & $260^{\circ} \mathrm{C}$ \\
\hline $1064 \mathrm{~nm}$ & $32^{\circ} \mathrm{C}$ & $256^{\circ} \mathrm{C}$ \\
\hline
\end{tabular}

Finally, bonding/debonding, self-healing and reshaping experiments were examined with glyfoma-based polymer. As shown in the Figure 27, bonding of two polymers films could be obtained upon irradiation at $785 \mathrm{~nm}$ for $10 \mathrm{~min}$. After irradiation, the two polymer pieces 
could not be separated anymore. Interestingly, comparisons with IR-813 used as a benchmarked NIR dye revealed this dye to be more efficient than SQ03. Indeed, only five minutes of irradiation were necessary to bond the two pieces together. If the approach is appealing for bonding/debonding applications, the keypoint of this strategy remains the photochemical and thermal stability of the NIR dyes over time once dispersed in the polymer. This point was not examined in this pioneering work.
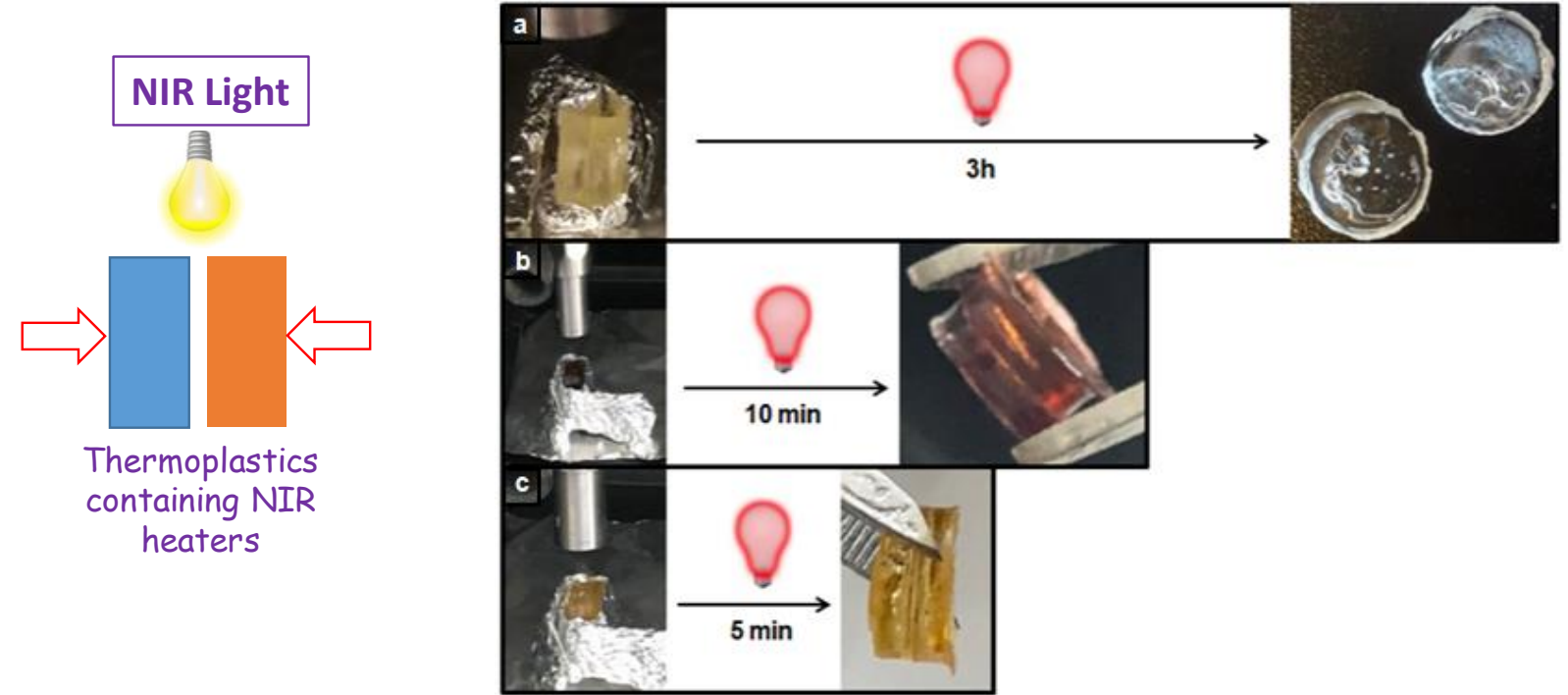

Figure 27. Examples of polymer bonding of two Glyfoma-based thermoplastic polymer films in contact upon irradiation from the top: (a) without heater (no bonding), (b) with $0.05 \%$ wt of SQ03 and (c) with $0.05 \%$ wt of IR-813 upon NIR light irradiation at $785 \mathrm{~nm}$ and $2.55 \mathrm{~W} / \mathrm{cm}^{2}$. Reproduced with permission of Ref. [60]

\section{Conclusion}

To conclude, three main families of squaraines have been examined since 2004 as visible light photoinitiators of polymerization. If 1,3-bis(arylamino)squaraines are well adapted for polymerization done in the near UV-visible range, 1,2 and 1,3-substituted squaraines are more adapted for polymerization in the near-infrared range (See Table 3). Concerning 1,2 and 1,3-squaraines, these dyes are characterized by high molar extinction coefficients, a property which is actively researched for photoinitiators of polymerization. If the scope of application of 1,3-bis(arylamino)squaraines was limited to FRP processes, 1,2 and 1,3-squaraines are more versatile photosensitizers since FPR and CP processes could be both initiated with these dyes. Among the most interesting finding which paves the way towards new applications of squaraines, their use in plastics recycling and reprocessing constitute a real revolution for squaraines. Indeed, beyond the simple photopolymerization of polymers, the life and the recycling of polymers has now to be considered prior to their syntheses. The first experiments of bonding/debonding, self-healing and reshaping prove that squaraines will be more widely studied in the Future. Indeed, families of NIR dyes are relatively limited and squaraines by their easiness of synthesis, their remarkable photochemical stabilities and low costs are certainly more promising than cyanines for these different innovative applications. 
Table 3. Summary of the optical properties of the different dyes discussed in this review.

\begin{tabular}{|c|c|c|}
\hline Squaraines & $\begin{array}{c}\text { Absorption maximum } \\
(\mathrm{nm})\end{array}$ & References \\
\hline SQP & 632 & [187] \\
\hline SQT & n.p. ${ }^{1}$ & [187] \\
\hline SQ1 & 400 & {$[199,200]$} \\
\hline SQ2 & 415 & [203] \\
\hline SQG1 & 400 & [207] \\
\hline SQG2 & 400 & [207] \\
\hline SQG3 & 400 & [207] \\
\hline SQG4 & 400 & [207] \\
\hline SQG5 & 400 & [207] \\
\hline SQG7 & 400 & [207] \\
\hline SQG8 & 400 & [207] \\
\hline SQG9 & 500 & [207] \\
\hline SQ02 & 653 & [221] \\
\hline SQ_1 & 521 & [61] \\
\hline SQ_2 & 514 & [61] \\
\hline SQ_3 & 525 & [61] \\
\hline SQ_4 & 610 & [61] \\
\hline SQm_1 & 663 & [61] \\
\hline SQm_2 & 645 & [61] \\
\hline SQm_3 & 457 & [61] \\
\hline SQm_4 & 632 & [61] \\
\hline SQ03 & 882 & [60] \\
\hline
\end{tabular}

${ }^{1}$ n.p. not provided.

\section{Acknowledgments}

The author thanks Aix Marseille University and the Centre National de la Recherche Scientifique for financial supports. This research was also funded by the Agence Nationale de la Recherche (ANR agency) through the PhD grant of Nicolas Giacoletto (ANR-19-CE07-0042, NOPEROX project).

\section{References}

[1] B. Ganster, U.K. Fischer, N. Moszner, R. Liska, New photocleavable structures. Diacylgermanebased photoinitiators for visible light curing, Macromolecules 41 (2008) 2394-2400.

[2] B. Ganster, U.K. Fischer, N. Moszner, R. Liska, New Photocleavable Structures, 4: AcylgermaneBased Photoinitiator for Visible Light Curing, Macromol. Rapid Commun. 29 (2008) 57-62. 
[3] W.D. Cook, F. Chen, Enhanced visible radiation photopolymerization of dimethacrylates with the three component thioxanthone (CPTXO)-amine-iodonium salt system, Polym. Chem. 6 (2015) 1325-1338.

[4] P. Xiao, Y. Wang, M. Dai, G. Wu, S. Shi, J. Nie, Synthesis and photopolymerization kinetics of benzophenone piperazine one-component initiator, Polym. Adv. Technol. 19 (2008) 409-413.

[5] N. Karaca, D.K. Balta, N. Ocal, N.J. Arsu, Mechanistic studies of thioxanthone-carbazole as a one-component type II photoinitiator, J. Lumin. 146 (2014) 424-429.

[6] D.S. Esen, G. Temel, D.K. Balta, X. Allonas, N. Arsu, One-component thioxanthone acetic acid derivative photoinitiator for free radical polymerization, Photochem. Photobiol. 90 (2014) 463469 .

[7] A. Vitale, M. Sangermano, R. Bongiovanni, P. Burtscher, N. Moszner, Visible light curable restorative composites for dental applications based on epoxy monomer, Materials 7 (2014) 554562.

[8] B.P. Fors, C. Hawker, Control of a living radical polymerization of methacrylates by light, J. Angew. Chem. Int. Ed. 51 (2012) 8850-8853.

[9] D. Konkolewicz, K. Schroöder, J. Buback, S. Bernhard, K. Matyjaszewski, Visible light and sunlight photoinduced ATRP with ppm of Cu catalyst. ACS Macro Lett. 1 (2012) 1219-1223.

[10] D.M. Haddleton, Polymer chemistry: Rooftop reactions, Nat. Chem. 5 (2013) 366-368.

[11] N.J. Treat, B.P. Fors, J.W. Kramer, M. Christianson, C.-Y. Chiu, J.R.D. Alaniz, C.J. Hawker, Controlled radical polymerization of acrylates regulated by visible light, ACS Macro Lett. 3 (2014) 580-584.

[12] J. Xu, C. Boyer, Visible light photocatalytic thiol-ene reaction: An elegant approach for fast polymer post-functionalization and step-growth polymerization, Macromolecules 48 (2015) 520-529.

[13] C. Dietlin, S. Schweizer, P. Xiao, J. Zhang, F. Morlet-Savary, B. Graff, J.-P. Fouassier, J. Lalevée, Photopolymerization upon LEDs: new photoinitiating systems and strategies, Polym. Chem. 6 (2015) 3895-3912.

[14] P. Garra, C. Dietlin, F. Morlet-Savary, F. Dumur, D. Gigmes, J.-P. Fouassier, J. Lalevée, Redox two-component initiated free radical and cationic polymerizations: Concepts, reactions and applications, Prog. Polym. Sci. 94 (2019) 33-56.

[15] J.-P. Fouassier, X. Allonas, D. Burget, Photopolymerization reactions under visible lights: principle, mechanisms and examples of applications, Prog. Org. Coat. 47 (2003) 16-36.

[16] P. Xiao, J. Zhang, F. Dumur, M.-A. Tehfe, F. Morlet-Savary, B. Graff, D. Gigmes, J.-P. Fouassier, J. Lalevée, Visible light sensitive photoinitiating systems: Recent progress in cationic and radical photopolymerization reactions under soft conditions, Prog. Polym. Sci. 41 (2015) 32-66.

[17] C. Mendes-Felipe, J. Oliveira, I. Etxebarria, J.L. Vilas-Vilela, S. Lanceros-Mendez, State-of-theart and future challenges of UV curable polymer-based smart materials for printing technologies, Adv. Mater. Technol. 4 (2019) 1800618. 
[18] V. Shukla, M. Bajpai, D.K. Singh, M. Singh, R. Shukla, Review of basic chemistry of UV-curing technology, Pigm. Resin Technol. 33 (2004) 272-279.

[19] M. Chen, M. Zhong, J.A. Johnson, Light-controlled radical polymerization: mechanisms, methods, and applications, Chem. Rev. 116 (2016) 10167-10211.

[20] J.V. Crivello, E. Reichmanis, Photopolymer materials and processes for advanced technologies, Chem. Mater. 26 (2014) 533-548.

[21] H. Kitano, K. Ramachandran, N.B. Bowden, A.B. Scranton, Unexpected visible-light-induced free radical photopolymerization at low light intensity and high viscosity using a titanocene photoinitiator, J. Appl. Polym. Sci. 128 (2013) 38259.

[22] N. Davidenko, O. García, R. Sastre, The efficiency of titanocene as photoinitiator in the polymerization of dental formulations, J. Biomater. Sci. Polym. Ed. 14 (2003) 733-746.

[23] M. Degirmenci, A. Onen, Y. Yagci, S.P. Pappas, Photoinitiation of cationic polymerization by visible light activated titanocene in the presence of onium salts, Polym. Bull. 46 (2011) 443-449.

[24] J. Lalevée, H. Mokbel, J.-P. Fouassier, Recent developments of versatile photoinitiating systems for cationic ring opening polymerization operating at any wavelengths and under low light intensity sources, Molecules 20 (2015) 7201-7221.

[25] M.-A. Tehfe, F. Louradour, J. Lalevée, J.-P. Fouassier, Photopolymerization reactions: On the way to a green and sustainable chemistry, Appl. Sci. 3 (2013) 490-514.

[26] R. Podsiadły, A. Maruszewska, R. Michalski, A. Marcinek, J. Kolinska, Naphthoylene benzimidazolone dyes as electron transfer photosensitizers for iodonium salt induced cationic photopolymerizations, Dyes Pigm. 95 (2012) 252-259.

[27] Z. Zhang, N. Corrigan, A. Bagheri, J. Jin, C. Boyer, A versatile 3D and 4D printing system through photocontrolled raft polymerization, Angew. Chem. 131 (2019) 18122-18131.

[28] A.Y. Lee, J. An, C.K. Chua, Two-way 4D-printing: A review on the reversibility of 3d-printed shape memory materials, Engineering 3 (2017) 663-674.

[29] A. Bagheri, J. Jin, Photopolymerization in 3D Printing, ACS Appl. Polym. Mater. 1 (2019) 593611.

[30] D.C. Aduba Jr., E.D. Margaretta, A.E.C. Marnot, K.V. Heifferon, W.R. Surbey, N.A. Chartrain, A.R. Whittington, T.E. Long, C.B. Williams, Vat photopolymerization 3D printing of acidcleavable PEG-methacrylate networks for biomaterial applications, Mater. Today Commun. 19 (2019) 204-211.

[31] J.-T. Lin, D.-C. Cheng, K.-T. Chen, H.-W. Liu, Dual-wavelength (UV and blue) controlled photopolymerization confinement for 3D-printing: Modeling and analysis of measurements, Polymers 11 (2019) 1819.

[32] E.A. Kamoun, A. Winkel, M. Eisenburger, H. Menzel, Carboxylated camphorquinone as visiblelight photoinitiator for biomedical application: Synthesis, characterization, and application, Arab. J. Chem. 9 (2016) 745-754. 
[33] A. Santini, I.T. Gallegos, C.M. Felix, Photoinitiators in dentistry: a review, Prim. Dent. J. 2 (2013) 30-33.

[34] J. Zhang, N. Zivic, F. Dumur, C. Guo, Y. Li, P. Xiao, B. Graff, D. Gigmes, J.-P. Fouassier, J. Lalevée, Panchromatic photoinitiators for radical, cationic and thiol-ene polymerization reactions: a search in the diketopyrrolopyrrole or indigo dye series, Mater. Today Commun. 4 (2015) 101-108.

[35] P. Xiao, W. Hong, Y. Li, F. Dumur, B. Graff, J.-P. Fouassier, D. Gigmes, J. Lalevée, Diketopyrrolopyrrole dyes: structure/reactivity/efficiency relationship in photoinitiating systems upon visible lights, Polymer 55 (2014) 746-751.

[36] P. Xiao, W. Hong, Y. Li, F. Dumur, B. Graff, J.-P. Fouassier, D. Gigmes, J. Lalevée, Green light sensitive diketopyrrolopyrrole derivatives used in versatile photoinitiating systems for photopolymerizations, Polym. Chem. 5 (2014) 2293-2300.

[37] M.-A. Tehfe, F. Dumur, P. Xiao, B. Graff, F. Morlet-Savary, J.-P. Fouassier, D. Gigmes, J. Lalevée, New chromone based photoinitiators for polymerization reactions upon visible lights, Polym. Chem. 4 (2013) 4234-4244.

[38] J. You, H. Fu, D. Zhao, T. Hu, J. Nie, T. Wang, Flavonol dyes with different substituents in photopolymerization, J. Photochem. Photobiol. A: Chem. 386 (2020) 112097.

[39] A. Al Mousawi, P. Garra, M. Schmitt, J. Toufaily, T. Hamieh, B. Graff, J.-P. Fouassier, F. Dumur, J. Lalevée, 3-Hydroxyflavone and $\mathrm{N}$-phenyl-glycine in high performance photo-initiating systems for 3D printing and photocomposites synthesis, Macromolecules 51 (2018) 4633-4641.

[40] J. Zhang, J. Lalevée, J. Zhao, B. Graff, M.H. Stenzel, P. Xiao, Dihydroxyanthraquinone derivatives: natural dyes as blue-light-sensitive versatile photoinitiators of photopolymerization, Polym. Chem. 7 (2016) 7316-7324.

[41] M. Abdallah, A. Hijazi, B. Graff, J.-P. Fouassier, G. Rodeghiero, A. Gualandi, F. Dumur, P.G. Cozzi, J. Lalevée, Coumarin derivatives as high performance visible light photoinitiators/photoredox catalysts for photosensitive resins for 3D printing technology, photopolymerization in water and photocomposites synthesis, Polym. Chem. 10 (2019) 872-884.

[42] Z. Li, X. Zou, G. Zhu, X. Liu, R. Liu, Coumarin-Based Oxime Esters: Photobleachable and Versatile Unimolecular Initiators for Acrylate and Thiol-Based Click Photopolymerization under Visible Light-Emitting Diode Light Irradiation, ACS Appl. Mater. Interfaces 10 (2018) 16113-16123.

[43] M. Abdallah, F. Dumur, A. Hijazi, G. Rodeghiero, A. Gualandi, P.G. Cozzi, J. Lalevée, Ketocoumarin scaffold for photo-initiators for 3D printing and photo-composites, J. Polym. Sci. 58 (2020) 1115-1129.

[44] M. Abdallah, A. Hijazi, F. Dumur, J. Lalevée, Coumarins as powerful photosensitizers for the cationic polymerization of epoxy-silicones under near-UV and visible light and applications for 3D printing technology, Molecules 25 (2020) 2063. 
[45] Q. Chen, Q. Yang, P. Gao, B. Chi, J. Nie, Y. He, Photopolymerization of coumarin-containing reversible photoresponsive materials based on wavelength selectivity, Ind. Eng. Chem. Res. 58 (2019) 2970-2975.

[46] M. Rahal, H. Mokbel, B. Graff, J. Toufaily, T. Hamieh, F. Dumur, J. Lalevée, Mono vs. difunctional coumarin as photoinitiators in photocomposite synthesis and 3D printing, Catalysts 10 (2020) 1202.

[47] M. Abdallah, A. Hijazi, P.G. Cozzi, A. Gualandi, F. Dumur, J. Lalevée, Boron compounds as additives for the cationic polymerization using coumarin derivatives in epoxy-silicones, Macromol. Chem. Phys. 222 (2021) 2000404.

[48] J. Lalevée, M. Peter, F. Dumur, D. Gigmes, N. Blanchard, M.-A. Tehfe, F. Morlet-Savary, J.-P. Fouassier, Subtle ligand effects in oxidative photocatalysis with iridium complexes: application to photopolymerization, Chem. Eur. J., 17 (2011) 15027-15031.

[49] J. Lalevée, M.-A. Tehfe, F. Dumur, D. Gigmes, N. Blanchard, F. Morlet-Savary, J.-P. Fouassier, Iridium photocatalysts in free radical photopolymerization under visible lights, ACS Macro Lett. 1 (2012) 286-290.

[50] J. Lalevée, F. Dumur, C.R. Mayer, D. Gigmes, G. Nasr, M.-A. Tehfe, S. Telitel, F. Morlet-Savary, B. Graff, J.-P. Fouassier, Photopolymerization of N-vinylcarbazole using visible-light harvesting iridium complexes as photoinitiators, Macromolecules 45 (2012) 4134-4141.

[51] S. Telitel, F. Dumur, S. Telitel, O. Soppera, M. Lepeltier, Y. Guillaneuf, J. Poly, F. Morlet-Savary, P. Fioux, J.-P. Fouassier, D. Gigmes, J. Lalevée, Photoredox catalysis using a new iridium complex as an efficient toolbox for radical, cationic and controlled polymerizations under soft blue to green lights, Polym. Chem. 6 (2015) 613-624.

[52] S. Telitel, F. Dumur, M. Lepeltier, D. Gigmes, J.-P. Fouassier, J. Lalevée, Photoredox process induced polymerization reactions: iridium complexes for panchromatic photo-initiating systems, C.R. Chimie 19 (2016) 71-78.

[53] M.-A. Tehfe, M. Lepeltier, F. Dumur, D. Gigmes, J.-P. Fouassier, J. Lalevée, Structural effects in the iridium complex series: photoredox catalysis and photoinitiation of polymerization reactions under visible lights, Macromol. Chem. Phys. 218 (2017) 1700192.

[54] F. Dumur, G. Nasr, G. Wantz, C.R. Mayer, E. Dumas, A. Guerlin, F. Miomandre, G. Clavier, D. Bertin, D. Gigmes, Cationic iridium complex for the design of soft salt-based phosphorescent OLEDs and color-tunable Light-Emitting Electrochemical Cells, Org. Electron. 12 (2011) 16831694.

[55] G. Nasr, A. Guerlin, F. Dumur, L. Beouch, E. Dumas, G. Clavier, F. Miomandre, F. Goubard, D. Gigmes, D. Bertin, G. Wantz, C.R. Mayer, Iridium (III) soft salts from dinuclear cationic and mononuclear anionic complexes for OLEDs devices, Chem. Commun. 47 (2011) 10698-10700.

[56] F. Dumur, D. Bertin, D. Gigmes, Iridium (III) complexes as promising emitters for solid-state light-emitting electrochemical cells (LECs), Int. J. Nanotechnol. 9 (2012) 377-395.

[57] M. Abdallah, T.-T. Bui, F. Goubard, D. Theodosopoulou, F. Dumur, A. Hijazi, J.-P. Fouassier, J. Lalevée, Phenothiazine derivatives as photoredox catalysts for cationic and radical 
photosensitive resins for 3D printing technology and photocomposites synthesis, Polym. Chem. 10 (2019) 6145-6156.

[58] H. Mokbel, F. Dumur, J. Lalevée, On demand NIR activated photopolyaddition reactions, Polym. Chem. 11 (2020) 4250-4259.

[59] H. Mokbel, B. Graff, F. Dumur, J. Lalevée, NIR sensitizer operating under long wavelength (1064 $\mathrm{nm}$ ) for free radical photopolymerization processes, Macromol. Rapid Commun. 41 (2020) 2000289 .

[60] V. Launay, A. Caron, G. Noirbent, D. Gigmes, F. Dumur, J. Lalevée, NIR dyes as innovative tools for reprocessing/recycling of plastics: Benefits of the photothermal activation in the nearinfrared range, Adv. Funct. Mater. 31 (2021) 2006324.

[61] A. Bonardi, F. Bonardi, G. Noirbent, F. Dumur, C. Dietlin, D. Gigmes, J.-P. Fouassier, J. Lalevée, Different NIR dye scaffolds for polymerization reactions under NIR light, Polym. Chem. 10 (2019) 6505-6514.

[62] H. Mokbel, J. Toufaily, T. Hamieh, F. Dumur, D. Campolo, D. Gigmes, J.-P. Fouassier, J. Ortyl, J. Lalevee, Specific cationic photoinitiators for Near UV and visible LEDs: Iodonium vs. ferrocenium structures, J. Appl. Polym. Sci. 132 (2015) 42759.

[63] S. Villotte, D. Gigmes, F. Dumur, J. Lalevée, Design of Iodonium Salts for UV or Near-UV LEDs for Photoacid Generator and Polymerization Purposes, Molecules 25 (2020) 149.

[64] N. Zivic, M. Bouzrati-Zerrelli, S. Villotte, F. Morlet-Savary, C. Dietlin, F. Dumur, D. Gigmes, J.P. Fouassier, J. Lalevée, A novel naphthalimide scaffold based iodonium salt as a onecomponent photoacid/photoinitiator for cationic and radical polymerization under LED exposure, Polym. Chem. 7 (2016) 5873-5879

[65] M. Abdallah, H. Le, A. Hijazi, B. Graff, F. Dumur, T.-T. Bui, F. Goubard, J.-P. Fouassier, J. Lalevée, Acridone derivatives as high performance visible light photoinitiators for cationic and radical photosensitive resins for 3D printing technology and for low migration photopolymer property, Polymer 159 (2018) 47-58.

[66] J. Zhang, F. Dumur, M. Bouzrati, P. Xiao, C. Dietlin, F. Morlet-Savary, B. Graff, D. Gigmes, J.-P. Fouassier, J. Lalevée, Novel panchromatic photopolymerizable matrices: $N, N^{\prime}$-dibutylquinacridone as an efficient and versatile photoinitiator, J. Polym. Sci. A Polym. Chem. 53 (2015) 1719-1727.

[67] P. Xiao, F. Dumur, D. Thirion, S. Fagour, S. Vacher, X. Sallenave, F. Morlet-Savary, B. Graff, J.P. Fouassier, D. Gigmes, J. Lalevée, Multicolor photoinitiators for radical and cationic polymerization: mono vs. poly functional thiophene derivatives, Macromolecules 46 (2013) 6786-6793.

[68] M.-A. Tehfe, F. Dumur, E. Contal, B. Graff, D. Gigmes, F. Morlet-Savary, J.-P. Fouassier, J. Lalevée, New insights in radical and cationic polymerizations upon visible light exposure: role of novel photoinitiator systems based on the pyrene chromophore, Polym. Chem. 4 (2013) 16251634. 
[69] S. Telitel, F. Dumur, T. Faury, B. Graff, M.-A. Tehfe, D. Gigmes, J.-P. Fouassier, J. Lalevée, New core-pyrene $\pi$-structure organophotocatalysts usable as highly efficient photoinitiators, Beilstein J. Org. Chem. 9 (2013) 877-890.

[70] N. Uchida, H. Nakano, T. Igarashi, T. Sakurai, nonsalt 1-(arylmethyloxy)pyrene photoinitiators capable of initiating cationic polymerization, J. Appl. Polym. Sci. 131 (2014) 40510.

[71] A. Mishra, S. Daswal, 1-(Bromoacetyl)pyrene, a novel photoinitiator for the copolymerization of styrene and methylmethacrylate, Rad. Phys. Chem. 75 (2006) 1093-1100.

[72] M.-A. Tehfe, F. Dumur, B. Graff, F. Morlet-Savary, D. Gigmes, J.-P. Fouassier, J. Lalevée, Design of new Type I \& Type II photoinitiators possessing highly coupled pyrene-ketone moieties, Polym. Chem. 4 (2013) 2313-2324.

[73] F. Dumur, Recent advances on pyrene-based photoinitiators of polymerization, Eur. Polym. J. 126 (2020) 109564.

[74] M.-A. Tehfe, J. Lalevée, F. Dumur, S. Telitel, D. Gigmes, E. Contal, D. Bertin, J.-P. Fouassier, Zinc-based metal complexes as new photocatalysts in polymerization initiating systems, Eur. Polym. J. 49 (2013) 1040-1049

[75] A.-H. Bonardi, S. Zahouily, C. Dietlin, B. Graff, F. Morlet-Savary, M. Ibrahim-Ouali, D. Gigmes, N. Hoffmann, F. Dumur, J. Lalevée, New 1,8-naphthalimide derivatives as photoinitiators for free radical polymerization upon visible light, Catalysts 9 (2019) 637.

[76] J. Zhang, N. Zivic, F. Dumur, P. Xiao, B. Graff, J.-P. Fouassier, D. Gigmes, J. Lalevée, Naphthalimide-tertiary amine derivatives as blue-light-sensitive photoinitiators, ChemPhotoChem 2 (2018) 481-489.

[77] P. Xiao, F. Dumur, J. Zhang, B. Graff, D. Gigmes, J.-P. Fouassier, J. Lalevée, Naphthalimide derivatives: substituent effects on the photoinitiating ability in polymerizations under near UV, purple, white and blue LEDs ( $385 \mathrm{~nm}, 395 \mathrm{~nm}, 405 \mathrm{~nm}, 455 \mathrm{~nm}$ or $470 \mathrm{~nm}$ ), Macromol. Chem. Phys. 216 (2015) 1782-1790.

[78] P. Xiao, F. Dumur, J. Zhang, B. Graff, D. Gigmes, J.-P. Fouassier, J. Lalevée, Naphthalimidephthalimide derivative based photoinitiating systems for polymerization reactions under blue lights, J. Polym. Sci. A Polym. Chem. 53 (2015) 665-674.

[79] J. Zhang, N. Zivic, F. Dumur, P. Xiao, B. Graff, D. Gigmes, J.-P. Fouassier, J. Lalevée, A benzophenone-naphthalimide derivative as versatile photoinitiator for near UV and visible lights, J. Polym. Sci. A Polym. Chem. 53 (2015) 445-451.

[80] J. Zhang, N. Zivic, F. Dumur, P. Xiao, B. Graff, J.-P. Fouassier, D. Gigmes, J. Lalevée, N-[2(dimethylamino)ethyl]-1,8-naphthalimide derivatives as photoinitiators under LEDs, Polym. Chem. 9 (2018) 994-1003.

[81] N. Zivic, J. Zhang, D. Bardelang, F. Dumur, P. Xiao, T. Jet, D.-L. Versace, C. Dietlin, F. MorletSavary, B. Graff, J.-P. Fouassier, D. Gigmes, J. Lalevée, Novel naphthalimideamine based photoinitiators operating under violet and blue LEDs and usable for various polymerization reactions and synthesis of hydrogels, Polym. Chem. 7 (2016) 418-429. 
[82] J. Zhang, F. Dumur, P. Xiao, B. Graff, D. Bardelang, D. Gigmes, J.-P. Fouassier, J. Lalevée, Structure design of naphthalimide derivatives: towards versatile photo-initiators for near UV/Visible LEDs, 3D printing and water-soluble photoinitiating systems, Macromolecules 48 (2015) 2054-2063.

[83] J. Zhang, N. Zivic, F. Dumur, P. Xiao, B. Graff, J.-P. Fouassier, D. Gigmes, J. Lalevée, UV violetblue LED induced polymerizations: specific photoinitiating systems at 365, 385, 395 and $405 \mathrm{~nm}$, Polymer 55 (2014) 6641-6648.

[84] P. Xiao, F. Dumur, B. Graff, D. Gigmes, J.-P. Fouassier, J. Lalevée, Blue light sensitive dyes for various photopolymerization reactions: naphthalimide and naphthalic anhydride derivatives, Macromolecules 47 (2014) 601-608.

[85] P. Xiao, F. Dumur, M. Frigoli, M.-A. Tehfe, B. Graff, J.-P. Fouassier, D. Gigmes, J. Lalevée, Naphthalimide based methacrylated photoinitiators in radical and cationic photopolymerization under visible light, Polym. Chem. 4 (2013) 5440-5448.

[86] G. Noirbent, F. Dumur, Recent advances on naphthalic anhydrides and 1,8-naphthalimidebased photoinitiators of polymerization, Eur. Polym. J. 132 (2020) 109702.

[87] M. Rahal, H. Mokbel, B. Graff, V. Pertici, D. Gigmes, J. Toufaily, T. Hamieh, F. Dumur, J. Lalevée, Naphthalimide-Based dyes as photoinitiators under visible light irradiation and their applications: photocomposite synthesis, 3D printing and polymerization in water, ChemPhotoChem (2021) 10.1002/cptc.202000306

[88] J. Li, X. Zhang, S. Ali, M.Y. Akram, J. Nie, X. Zhu, The effect of polyethylene glycoldiacrylate complexation on type II photoinitiator and promotion for visible light initiation system, J. Photochem. Photobiol. A: Chem. 384 (2019) 112037.

[89] J. Li, S. Li, Y. Li, R. Li, J. Nie, X. Zhu, In situ monitoring of photopolymerization by photoinitiator with luminescence characteristics, J. Photochem. Photobiol. A: Chem. 389 (2020) 112225.

[90] J. Li, Y. Hao, M. Zhong, L. Tang, J. Nie, X. Zhu, Synthesis of furan derivative as LED light photoinitiator: One-pot, low usage, photobleaching for light color 3D printing, Dyes Pigm. 165 (2019) 467-473.

[91] Y. Xu, G. Noirbent, D. Brunel, Z. Ding, D. Gigmes, B. Graff, P. Xiao, F. Dumur, J. Lalevée, Novel ketone derivatives based photoinitiating systems for free radical polymerization under mild conditions and 3D printing, Polym. Chem. 11 (2020) 5767-5777.

[92] J. Zhang, D. Campolo, F. Dumur, P. Xiao, D. Gigmes, J.-P. Fouassier, J. Lalevée, The carbazolebound ferrocenium salt as a specific cationic photoinitiator upon near-UV and visible LEDs (365-405 nm), Polym. Bull. 73 (2016) 493-507.

[93] A. Al Mousawi, F. Dumur, J. Toufaily, T. Hamieh, B. Graff, D. Gigmes, J.-P. Fouassier, J. Lalevée, Carbazole scaffold based photoinitiators/photoredox catalysts for new LED projector 3D printing resins, Macromolecules 50 (2017) 2747-2758.

[94] A. Al Mousawi, D. Magaldi Lara, G. Noirbent, F. Dumur, J. Toufaily, T. Hamieh, T.-T. Bui, F. Goubard, B. Graff, D. Gigmes, J.-P. Fouassier, J. Lalevée, Carbazole derivatives with thermally 
activated delayed fluorescence property as photoinitiators/photoredox catalysts for LED 3D printing technology, Macromolecules 50 (2017) 4913-4926.

[95] A. Al Mousawi, P. Garra, F. Dumur, T.-T. Bui, F. Goubard, J. Toufaily, T. Hamieh, B. Graff, D. Gigmes, J.-P. Fouassier, J. Lalevée, Novel Carbazole Skeleton-Based Photoinitiators for LED Polymerization and LED Projector 3D Printing, Molecules 22 (2018) 2143.

[96] A. Al Mousawi, A. Arar, M. Ibrahim-Ouali, S. Duval, F. Dumur, P. Garra, J. Toufaily, T. Hamieh, B. Graff, D. Gigmes, J.-P. Fouassier, J. Lalevée, Carbazole-based compounds as photoinitiators for free radical and cationic polymerization upon near visible light illumination, Photochem. Photobiol. Sci. 17 (2018) 578-585.

[97] M. Abdallah, D. Magaldi, A. Hijazi, B. Graff, F. Dumur, J.-P. Fouassier, T.-T. Bui, F. Goubard, J. Lalevée, Development of new high performance visible light photoinitiators based on carbazole scaffold and their applications in 3D printing and photocomposite synthesis, J. Polym. Sci. A Polym. Chem. 57 (2019) 2081-2092.

[98] S. Liu, H. Chen, Y. Zhang, K. Sun, Y. Xu, F. Morlet-Savary, B. Graff, G. Noirbent, C. Pigot, D. Brunel, M. Nechab, D. Gigmes, P. Xiao, F. Dumur, J. Lalevée, Monocomponent photoinitiators based on benzophenone-carbazole structure for led photoinitiating systems and application on 3D printing, Polymers 12 (2020) 1394 (2020).

[99] P. Xiao, F. Dumur, B. Graff, D. Gigmes, J.-P. Fouassier, J. Lalevée, Variations on the benzophenone skeleton: novel high-performance blue light sensitive photoinitiating systems, Macromolecules 46 (2013) 7661-7667.

[100] J. Zhang, M. Frigoli, F. Dumur, P. Xiao, L. Ronchi, B. Graff, F. Morlet-Savary, J.-P. Fouassier, D. Gigmes, J. Lalevée, Design of novel photoinitiators for radical and cationic photopolymerizations under Near UV and Visible LEDs (385, 395 and $405 \mathrm{~nm}$ ), Macromolecules 47 (2014) 2811-2819.

[101] S. Liu, D. Brunel, G. Noirbent, A. Mau, H. Chen, F. Morlet-Savary, B. Graff, D. Gigmes, P. Xiao, F. Dumur, J. Lalevée, New multifunctional benzophenone-based photoinitiators with high migration stability and their application in 3D printing, Mater. Chem. Front. 5 (2021) 1982-1994.

[102] S. Liu, D. Brunel, K. Sun, Y. Zhang, H. Chen, P. Xiao, F. Dumur, J. Lalevée, Novel photoinitiators based on benzophenone-triphenylamine hybrid structure for led photopolymerization, Macromol. Rapid Commun. 41 (2020) 2000460.

[103] S. Liu, D. Brunel, K. Sun, Y. Xu, F. Morlet-Savary, B. Graff, P. Xiao, F. Dumur, J. Lalevée, A mono-component bifunctional benzophenone-carbazole type II photoinitiator for led photoinitiating systems, Polym. Chem. 11 (2020) 3551-3556.

[104] N. Karaca, N. Ocala, N. Arsua, S. Jockusch, Thioxanthone-benzothiophenes as photoinitiator for free radical polymerization, J. Photochem. Photobiol. A: Chem. 331 (2016) 22-28.

[105] Q. Wu, X. Wang, Y. Xiong, J. Yang, H. Tang, Thioxanthone based one-component polymerizable visible light photoinitiator for free radical polymerization, RSC Adv. 6 (2016) 66098-66107.

[106] J. Qiu, J. Wei, Thioxanthone photoinitiator containing polymerizable $\mathrm{N}$-aromatic maleimide for photopolymerization, J. Polym. Res. 21 (2014) 559. 
[107] S. Dadashi-Silab, C. Aydogan, Y. Yagci, Shining a light on an adaptable photoinitiator: advances in photopolymerizations initiated by thioxanthones, Polym. Chem. 6 (2015) 6595-6615.

[108] J. Guit, M.B.L. Tavares, J. Hul, C. Ye, K. Loos, J. Jager, R. Folkersma, V.S.D. Voet, Photopolymer Resins with Biobased Methacrylates Based on Soybean Oil for Stereolithography, ACS Appl. Polym. Mater. 2 (2020) 949-957

[109] M.-A. Tehfe, F. Dumur, E. Contal, B. Graff, D. Gigmes, J.-P. Fouassier, J. Lalevée, Novel highly efficient organophotocatalysts: truxene-acridine-1,8-diones as photoinitiators of polymerization, Macromol. Chem. Phys. 214 (2013) 2189-2201.

[110] P. Xiao, F. Dumur, M.-A. Tehfe, B. Graff, D. Gigmes, J.-P. Fouassier, J. Lalevée, Difunctional acridinediones as photoinitiators of polymerization under UV and visible lights: structural effects, Polymer 54 (2013) 3458-3466.

[111] P. Xiao, F. Dumur, M.-A. Tehfe, B. Graff, D. Gigmes, J.-P. Fouassier, J. Lalevée, Acridinediones: effect of substituents on their photoinitiating abilities in radical and cationic photopolymerization, Macromol. Chem. Phys. 214 (2013) 2276-2282.

[112] P. Xiao, F. Dumur, M. Frigoli, B. Graff, F. Morlet-Savary, G. Wantz, H. Bock, J.-P. Fouassier, D. Gigmes, J. Lalevée, Perylene derivatives as photoinitiators in blue light sensitive cationic or radical curable films and panchromatic thiol-ene polymerizable films, Eur. Polym. J. 53 (2014) 215-222.

[113] M.-A. Tehfe, F. Dumur, B. Graff, D. Gigmes, J.-P. Fouassier, J. Lalevée, Green light induced cationic ring opening polymerization reactions: perylene-3,4:9,10-bis(dicarboximide) as efficient photosensitizers, Macromol. Chem. Phys. 214 (2013) 1052-1060.

[114] P. Xiao, F. Dumur, B. Graff, D. Gigmes, J.-P. Fouassier, J. Lalevée, Red-light-induced cationic photopolymerization: perylene derivatives as efficient photoinitiators, Macromol. Rapid Commun. 34 (2013) 1452-1458.

[115] P. Xiao, F. Dumur, J. Zhang, J.-P. Fouassier, D. Gigmes, J. Lalevée, Copper complexes in radical photoinitiating systems: applications to free radical and cationic polymerization under visible lights, Macromolecules 47 (2014) 3837-3844.

[116] P. Xiao, F. Dumur, J. Zhang, D. Gigmes, J.-P. Fouassier, J. Lalevée, Copper complexes: the effect of ligands on their photoinitiation efficiencies in radical polymerization reactions under visible light, Polym. Chem. 5 (2014) 6350-6357.

[117] P. Xiao, J. Zhang, D. Campolo, F. Dumur, D. Gigmes, J.-P. Fouassier, J. Lalevée, Copper and iron complexes as visible-light-sensitive photoinitiators of polymerization, J. Polym. Sci. A Polym. Chem. 53 (2015) 2673-2684.

[118] A. Al Mousawi, A. Kermagoret, D.-L. Versace, J. Toufaily, T. Hamieh, B. Graff, F. Dumur, D. Gigmes, J.-P. Fouassier, J. Lalevée, Copper photoredox catalysts for polymerization upon near UV or visible light: structure/reactivity/ efficiency relationships and use in LED projector 3D printing resins, Polym. Chem. 8 (2017) 568-580.

[119] P. Garra, A. Kermagoret, A. Al Mousawi, F. Dumur, D. Gigmes, F. Morlet-Savary, C. Dietlin, J.P. Fouassier, J. Lalevée, New copper(I) complex based initiating systems in redox 
polymerization and comparison with the amine/benzoyl peroxide reference, Polym. Chem. 8 (2017) 4088-4097.

[120] P. Garra, F. Dumur, F. Morlet-Savary, C. Dietlin, D. Gigmes, J.-P. Fouassier, J. Lalevée, Mechanosynthesis of a copper complex for redox initiating systems with a unique near infrared light activation, J. Polym. Sci. A Polym. Chem. 55 (2017) 3646-3655.

[121] H. Mokbel, D. Anderson, R. Plenderleith, C. Dietlin, F. Morlet-Savary, F. Dumur, D. Gigmes, J.P. Fouassier, J. Lalevée, Copper PhotoRedox Catalyst "G1": A New High Performance Photoinitiator for Near-UV and Visible LEDs, Polym. Chem. 8 (2017) 5580-5592.

[122] P. Garra, F. Dumur, A. Al Mousawi, B. Graff, D. Gigmes, F. Morlet-Savary, C. Dietlin, J.-P. Fouassier, J. Lalevée, Mechanosynthesized Copper (I) complex based initiating systems for redox polymerization: towards upgraded oxidizing and reducing agents, Polym. Chem. 8 (2017) 5884-5896.

[123] P. Garra, M. Carré, F. Dumur, F. Morlet-Savary, C. Dietlin, D. Gigmes, J.-P. Fouassier, J. Lalevée, Copper-based (photo) redox initiating systems as highly efficient systems for interpenetrating polymer network preparation, Macromolecules 51 (2018) 679-688.

[124] P. Garra, F. Dumur, M. Nechab, F. Morlet-Savary, C. Dietlin, B. Graff, D. Gigmes, J.-P. Fouassier, J. Lalevée, Stable copper acetylacetonate-based oxidizing agents in redox (NIR photoactivated) polymerization: an opportunity for one pot grafting from approach and example on a 3D printed object, Polym. Chem. 9 (2018) 2173-2182.

[125] H. Mokbel, D. Anderson, R. Plenderleith, C. Dietlin, F. Morlet-Savary, F. Dumur, D. Gigmes, J.P. Fouassier, J. Lalevée, Simultaneous initiation of radical and cationic polymerization reactions using the "G1" copper complex as photoRedox catalyst: Applications of free radical/cationic hybrid photo-polymerization in the composites and 3D printing fields, Prog. Org. Coat. 132 (2019) 50-61.

[126] A. Al Mousawi, F. Dumur, P. Garra, J. Toufaily, T. Hamieh, F. Goubard, T.-T. Bui, B. Graff, D. Gigmes, J.-P. Fouassier, J. Lalevée, Azahelicenes as visible light photoinitiators for cationic and radical polymerization: preparation of photo-luminescent polymers and use in high performance LED projector 3D printing resins, J. Polym. Sci. A Polym. Chem. 55 (2017) 11891199.

[127] A. Al Mousawi, M. Schmitt, F. Dumur, J. Ouyang, L. Favereaud, V. Dorcet, N. Vanthuyne, P. Garra, J. Toufaily, T. Hamieh, B. Graff, J.-P. Fouassier, D. Gigmes, J. Crassous, J. Lalevée, Visible light chiral photoinitiator for radical polymerization and synthesis of polymeric films with strong chiroptical activity, Macromolecules 51 (2018) 5628-5637.

[128] H. Chen, G. Noirbent, Y. Zhang, K. Sun, S. Liu, D. Brunel, D. Gigmes, B. Graff, F. Morlet-Savary, P. Xiao, F. Dumur, J. Lalevée, Photopolymerization and 3D/4D applications using newly developed dyes: search around the natural chalcone scaffold in photoinitiating systems, Dyes Pigm. 188 (2021) 109213.

[129] M.-A. Tehfe, F. Dumur, P. Xiao, M. Delgove, B. Graff, J.-P. Fouassier, D. Gigmes, J. Lalevée, Chalcone derivatives as highly versatile photoinitiators for radical, cationic, thiol-ene and IPN polymerization reactions upon visible lights, Polym. Chem. 5 (2014) 382-390. 
[130] L. Tang, J. Nie, X. Zhu, A high performance phenyl-free LED photoinitiator for cationic or hybrid photopolymerization and its application in LED cationic 3D printing, Polym. Chem. 11 (2020) 2855-2863.

[131] Y. Xu, G. Noirbent, D. Brunel, Z. Ding, D. Gigmes, B. Graff, P. Xiao, F. Dumur, J. Lalevée, Allyloxy ketones as efficient photoinitiators with high migration stability in free radical polymerization and 3D printing, Dyes Pigm. 185 (2021) 108900.

[132] Y. Xu, Z. Ding, H. Zhu, B. Graff, P. Xiao, F. Dumur, J. Lalevée, Design of ketone derivatives as highly efficient photoinitiators for free radical and cationic photopolymerizations and application in 3D printing of composites, J. Polym. Sci. (2021) 10.1002/pol.20200658.

[133] H. Chen, G. Noirbent, Y. Zhang, D. Brunel, D. Gigmes, S. Liu, K. Sun, F. Morlet-Savary, B. Graff, P. Xiao, F. Dumur, J. Lalevée, Novel D- $\pi-A$ and A- $\pi-D-\pi-A$ three-component photoinitiating systems based on carbazole/triphenylamino based chalcones and application in $3 \mathrm{D}$ and $4 \mathrm{D}$ Printing, Polym. Chem. 11 (2020) 6512-6528.

[134] H. Chen, G. Noirbent, S. Liu, D. Brunel, B. Graff, D. Gigmes, Y. Zhang, K. Sun, F. Morlet-Savary, P. Xiao, F. Dumur, J. Lalevée, Bis-chalcone derivatives derived from natural products as nearUV/visible light sensitive photoinitiators for 3D/4D printing, Mater. Chem. Front. 5 (2021) 901916.

[135] Y. Xu, Z. Ding, H. Zhu, B. Graff, P. Xiao, F. Dumur, J. Lalevée, Design of ketone derivatives as highly efficient photoinitiators for free radical and cationic photopolymerizations and application in 3D printing of composites, J. Polym. Sci. 58 (2020) 3432-3445.

[136] S. Liu, Y. Zhang, K. Sun, B. Graff, P. Xiao, F. Dumur, J. Lalevée, Design of photoinitiating systems based on the chalcone-anthracene scaffold for led cationic photopolymerization and application in 3D Printing, Eur. Polym. J. 147 (2021) 110300.

[137] M.-A. Tehfe, A. Zein-Fakih, J. Lalevée, F. Dumur, D. Gigmes, B. Graff, F. Morlet-Savary, T. Hamieh, J.-P. Fouassier, New pyridinium salts as versatile compounds for dye sensitized photopolymerization, Eur. Polym. J. 49 (2013) 567-574.

[138] P. Xiao, M. Frigoli, F. Dumur, B. Graff, D. Gigmes, J.-P. Fouassier, J. Lalevée, Julolidine or fluorenone based push-pull dyes for polymerization upon soft polychromatic visible light or green light, Macromolecules 47 (2014) 106-112.

[139] M.-A. Tehfe, F. Dumur, B. Graff, F. Morlet-Savary, J.-P. Fouassier, D. Gigmes, J. Lalevée, New push-pull dyes derived from Michler's ketone for polymerization reactions upon visible lights, Macromolecules 46 (2013) 3761-3770.

[140] H. Mokbel, F. Dumur, C.R. Mayer, F. Morlet-Savary, B. Graff, D. Gigmes, J. Toufaily, T. Hamieh, J.-P. Fouassier, J. Lalevée, End capped polyenic structures as visible light sensitive photoinitiators for polymerization of vinylethers, Dyes Pigm. 105 (2014) 121-129.

[141] P. Garra, D. Brunel, G. Noirbent, B. Graff, F. Morlet-Savary, C. Dietlin, V.F. Sidorkin, F. Dumur, D. Duché, D. Gigmes, J.-P. Fouassier, J. Lalevée, Ferrocene-based (photo)redox polymerization under long wavelengths, Polym. Chem. 10 (2019) 1431-1441. 
[142] S. Telitel, F. Dumur, T. Kavalli, B. Graff, F. Morlet-Savary, D. Gigmes, J.-P. Fouassier, J. Lalevée, The 1,3-bis(dicyanomethylidene)-indane skeleton as a (photo) initiator in thermal ring opening polymerization at RT and radical or cationic photopolymerization, RSC Adv. 4 (2014) 1593015936.

[143] H. Mokbel, F. Dumur, B. Graff, C.R. Mayer, D. Gigmes, J. Toufaily, T. Hamieh, J.-P. Fouassier, J. Lalevée, Michler's ketone as an interesting scaffold for the design of high-performance dyes in photoinitiating systems upon visible lights, Macromol. Chem. Phys. 215 (2014) 783-790.

[144] K. Sun, S. Liu, C. Pigot, D. Brunel, B. Graff, M. Nechab, D. Gigmes, F. Morlet-Savary, Y. Zhang, P. Xiao, F. Dumur, J. Lalevée, Novel push-pull dyes derived from $1 \mathrm{H}-$ cyclopenta[b]naphthalene-1,3(2H)-dione as versatile photoinitiators for photopolymerization and their related applications: 3D-printing and fabrication of photocomposites, Catalysts 10 (2020) 1196.

[145] M.-A. Tehfe, F. Dumur, B. Graff, F. Morlet-Savary, D. Gigmes, J.-P. Fouassier, J. Lalevée, Pushpull (thio)barbituric acid derivatives in dye photosensitized radical and cationic polymerization reactions under 457/473 nm laser beams or blue LEDs. Polym. Chem. 4 (2013) 3866-3875.

[146] F. Dumur, D. Gigmes, J.-P. Fouassier, J. Lalevée, Organic Electronics: an El Dorado in the quest of new photoCatalysts as photoinitiators of polymerization, Acc. Chem. Res. 49 (2016) 19801989.

[147] K. Sun, S. Liu, H. Chen, F. Morlet-Savary, B. Graff, C. Pigot, M. Nechab, P. Xiao, F. Dumur, J. Lalevée, N-ethylcarbazole-1-allylidene-based push-pull dyes as efficient light harvesting photoinitiators for sunlight induced polymerization, Eur. Polym. J. 147 (2021) 110331.

[148] F. Dumur, Recent advances on visible light photoinitiators of polymerization based on indane1,3-dione and related derivatives, Eur. Polym. J. 143 (2021) 110178.

[149] A. Al Mousawi, C. Poriel, F. Dumur, J. Toufaily, T. Hamieh, J.-P. Fouassier, J. Lalevée, Zinc tetraphenylporphyrin as high performance visible-light photoinitiator of cationic photosensitive resins for LED projector 3D printing applications, Macromolecules 50 (2017) 746753.

[150] G. Noirbent, Y. Xu, A.-H. Bonardi, D. Gigmes, J. Lalevée, F. Dumur, Metalated Porphyrins as versatile visible light and NIR photoinitiators of polymerization, Eur. Polym. J. 139 (2020) 110019

[151] J. Zhang, D. Campolo, F. Dumur, P. Xiao, J.-P. Fouassier, D. Gigmes, J. Lalevée, Iron complexes as photoinitiators for radical and cationic polymerization through photoredox catalysis processes, J. Polym. Sci. A Polym. Chem. 53 (2015) 42-49.

[152] S.Telitel, F. Dumur, D. Campolo, J. Poly, D. Gigmes, J.-P. Fouassier, J. Lalevée, Iron complexes as potential photocatalysts for controlled radical photopolymerizations: A tool for modifications and patterning of surfaces, J. Polym. Sci. A Polym. Chem. 54 (2016) 702-713.

[153] J. Zhang, D. Campolo, F. Dumur, P. Xiao, J.-P. Fouassier, D. Gigmes, J. Lalevée, Visible-lightsensitive photoredox catalysis by iron complexes: applications in cationic and radical polymerization reactions, J. Polym. Sci. A Polym. Chem. 54 (2016) 2247-2253. 
[154] J. Zhang, D. Campolo, F. Dumur, P. Xiao, J.-P. Fouassier, D. Gigmes, J. Lalevée, Novel iron complexes in visible-light-sensitive photoredox catalysis: effect of ligands on their photoinitiation efficiencies, ChemCatChem 8 (2016) 2227-2233.

[155] J. Zhang, F. Dumur, P. Horcajada, C. Livage, P. Xiao, J.-P. Fouassier, D. Gigmes, J. Lalevée, Ironbased metal-organic frameworks (MOF) as photocatalysts for radical and cationic polymerizations under near UV and visible LEDs (385 - 405 nm), Macromol. Chem. Phys. 217 (2016) 2534-2540.

[156] F. Dumur, Recent advances on ferrocene-based photoinitiating systems, Eur. Polym. J. 147 (2021) 110328.

[157] P. Garra, C. Dietlin, F. Morlet-Savary, F. Dumur, D. Gigmes, J.-P. Fouassier, J. Lalevée, Photopolymerization of thick films and in shadow areas: A review for the access to composites, Polym. Chem. 8 (2017) 7088-7101.

[158] P. Garra, A.-H. Bonardi, A. Baralle, A. Al Mousawi, F. Bonardi, C. Dietlin, F. Morlet-Savary, J.P. Fouassier, J. Lalevée, Monitoring Photopolymerization Reactions through Thermal Imaging: A Unique Tool for the Real-Time Follow-Up of Thick Samples, 3D Printing, and Composites, J. Polym. Sci. A Polym. Chem. 56 (2018) 889-899.

[159] Y. Zhang, L. Josien, J.-P. Salomon, A. Simon-Masseron, J. Lalevée, Photopolymerization of Zeolite/Polymer-Based Composites: toward 3D and 4D Printing Applications, ACS Appl. Polym. Mater. (2021) 10.1021/acsapm.0c01170.

[160] L. Breloy, C. Negrell, A.-S. Mora, W.S.J. Li, V. Brezová, S. Caillol, D.-L. Versace, Vanillin Derivative as Performing Type I Photoinitiator, Eur. Polym. J. 132 (2020) 109727.

[161] C. Dietlin, T.T. Trinh, S. Schweizer, B. Graff, F. Morlet-Savary, P.-A. Noirot, J. Lalevée, New Phosphine Oxides as High Performance Near-UV Type I Photoinitiators of Radical Polymerization, Molecules 25 (2020) 1671.

[162] A. Eibel, D.E. Fast, G. Gescheidt, Choosing the ideal photoinitiator for free radical photopolymerizations: predictions based on simulations using established data, Polym. Chem. 9 (2018) 5107-5115.

[163] S. Dadashi-Silab, S. Doran, Y. Yagci, Photoinduced Electron Transfer Reactions for Macromolecular Syntheses, Chem. Rev. 116 (2016) 10212-10275.

[164] N. Corrigan, S. Shanmugam, J. Xu, C. Boyer, Photocatalysis in organic and polymer synthesis, Chem. Soc. Rev. 45 (2016) 6165-6212.

[165] J. Lalevée, M.-A. Tehfe, F. Morlet-Savary, B. Graff, F. Dumur, D. Gigmes, N. Blanchard, J.-P. Fouassier, Photoredox catalysis for polymerization reactions, Chimia 66 (2012) 439-441.

[166] A.-H. Bonardi, F. Dumur, G. Noirbent, J. Lalevée, D. Gigmes, Organometallic vs organic photoredox catalysts for photocuring reactions in the visible region, Beilstein J. Org. Chem. 14 (2018) 3025-3046. 
[167] J.-P. Fouassier, J. Lalevée, Photochemical Production of Interpenetrating Polymer Networks; Simultaneous Initiation of Radical and Cationic Polymerization Reactions, Polymers 6 (2014) 2588-2610.

[168] W. Tomal, A. Chachaj-Brekiesz, R. Popielarz, J. Ortyl, Multifunctional biphenyl derivatives as photosensitisers in various types of photopolymerization processes, including IPN formation, 3D printing of photocurable multiwalled carbon nanotubes (MWCNTs) fluorescent composites, RSC Adv. 10 (2020) 32162-32182.

[169] J. Lalevée, F. Morlet-Savary, C. Dietlin, B. Graff, J.-P. Fouassier, Photochemistry and Radical Chemistry under Low Intensity Visible Light Sources: Application to Photopolymerization Reactions, Molecules 19 (2014) 15026-15041.

[170] E. Andrzejewska, K. Grajek, Recent advances in photo-induced free-radical polymerization. MOJ Poly Sci. 1 (2017) 58-60.

[171] R. Turrisi, L. Mascheroni, M. Sassi, M. Rooney, N. Buccheri, R. Ruffo, A. Facchetti, L. Beverina, Synthesis and Characterization of Squaraine-Based Photocrosslinkable Resists for Bulk Heterojunction Solar Cells, Eur. J. Org. Chem. 23 (2016) 4032-4040.

[172] G. Chen, H. Sasabe, T. Igarashi, Z. Hong, J. Kido, Squaraine dyes for organic photovoltaic cells, J. Mater. Chem. A, 3 (2015) 14517-14534.

[173] Y. Chen, G. Wang, L. Yang, J. Wu, F.S. Melkonyan, Y. Huang, Z. Lu, T.J. Marks, A. Facchetti, Novel unsymmetrical squaraine-based small molecules for organic solar cells, J. Mater. Chem. C 6 (2018) 847-854.

[174] S.A. Al-horaibi, A.M. Asiri, R.M. El-Shishtawy, S.T. Gaikwad, A.S. Rajbhoj, Synthesis and characterization of new squaraine dyes with bispendent carboxylic groups for dye-sensitized solar cells, J. Mol. Struct. 1195 (2019) 850-858.

[175] G. Xia, H. Wang, Squaraine dyes: The hierarchical synthesis and its application in optical detection, J. Photochem. Photobiol. C: Photochem. Rev. 31 (2017) 84-113.

[176] K. Ilina, W.M. MacCuaig, M. Laramie, J.N. Jeouty, L.R. McNally, M. Henary, Squaraine Dyes: Molecular Design for Different Applications and Remaining Challenges, Bioconjugate Chem. 31 (2020) 194-213.

[177] D. Yao, Y. Wang, R. Zou, K. Bian, P. Liu, S. Shen, W. Yang, B. Zhang, D. Wang, Molecular Engineered Squaraine Nanoprobe for NIR-II/Photoacoustic Imaging and Photothermal Therapy of Metastatic Breast Cancer, ACS Appl. Mater. Interf. 12 (2020) 4276-4284.

[178] F.-P. Gao, Y.-X. Lin, L.-L. Li, Y. Liu, U. Mayerhöffer, P. Spenst, J.-G. Su, J.-Y. Li, F. Würthner, H. Wang, Supramolecular adducts of squaraine and protein for noninvasive tumor imaging and photothermal therapy in vivo, Biomaterials 35 (2014) 1004-1014.

[179] S. Sreejith, J. Joseph, M. Lin, N. Venugopal Menon, P. Borah, H.J. Ng, Y.X. Loong, Y. Kang, S. Wing-Kwong Yu, Y. Zhao, Near-Infrared Squaraine Dye Encapsulated Micelles for in Vivo Fluorescence and Photoacoustic Bimodal Imaging, ACS Nano 9 (2015) 5695-5704. 
[180] W.E. Meador, S.A. Autry, R.N. Bessetti, J.N. Gayton, A.S. Flynt, N.I. Hammer, J.H. Delcamp, Water-Soluble NIR Absorbing and Emitting Indolizine Cyanine and Indolizine Squaraine Dyes for Biological Imaging, J. Org. Chem. 85 (2020) 4089-4095.

[181] C. Butnarasu, N. Barbero, C. Barolo, S. Visentin, Squaraine dyes as fluorescent turn-on sensors for the detection of porcine gastric mucin: A spectroscopic and kinetic study, J. Photochem. Photobiol. B Biol. 205 (2020) 111838.

[182] A. Treibs, K. Jacob, Cyclotrimethine Dyes Derived from Squaric Acid, Angew. Chem. Int. Ed. 4 (1965) 694-694.

[183] E. Ronchi, R. Ruffo, S. Rizzato, A. Albinati, L. Beverina, G.A. Pagani, Regioselective Synthesis of 1,2- vs 1,3-Squaraines, Org. Lett. 13 (2011) 3166-3169.

[184] L. Beverina, R. Ruffo, M.M. Salamone, E. Ronchi, M. Binda, D. Natali, M. Sampietro, Panchromatic squaraine compounds for broad band light harvesting electronic devices, J. Mater. Chem. 22 (2012) 6704-6710.

[185] G. Xia, H. Wang, Squaraine dyes: The hierarchical synthesis and its application in optical detection, Journal of Photochemistry and Photobiology C: Photochemistry Reviews 31 (2017) 84-113.

[186] D. Yang, Z. Guan, L. Yang, Y. Huang, Q. Wei, Z. Lu, J. Yu, Novel high-performance photovoltaic D-A conjugated polymers bearing1,2-squaraine moieties as electron-deficient units, Sol. Energy Mater. Sol. Cells 105 (2012) 220-228.

[187] Y. He, W. Zhou, F. Wu, M. Li, E. Wang, Photoreaction and photopolymerization studies on squaraines dyes/iodonium salts combination, J. Photochem. Photobiol. A Chem. 162 (2004) 463471.

[188] D. Ramaiah, I. Eckert, K.T. Arun, L. Weidenfeller, B. Epe, Squaraine Dyes for Photodynamic Therapy: Study of Their Cytotoxicity and Genotoxicity in Bacteria and Mammalian Cells, Photochem. Photobiol. 76 (2002) 672-677.

[189] G. Xia, H. Wang, Squaraine dyes: The hierarchical synthesis and its application in optical detection, J. Photochem. Photobiol. C Photochem. Rev. 31 (2017) 84-113.

[190] E. Lima, R.E. Boto, D. Ferreira, J.R. Fernandes, P. Almeida, L.F.V. Ferreira, E.B. Souto, A.M. Silva, L.V. Reis, Quinoline- and Benzoselenazole-Derived Unsymmetrical Squaraine Cyanine Dyes: Design, Synthesis, Photophysicochemical Features and Light-Triggerable Antiproliferative Effects against Breast Cancer Cell Lines, Materials 13 (2020), 2646.

[191] W. Liu, H.H. McGarraugh, B.D. Smith, Fluorescent Thienothiophene-Containing Squaraine Dyes and Threaded Supramolecular Complexes with Tunable Wavelengths between 600-800 nm, Molecules 23 (2018) 2229.

[192] T.D. Martins, E. Lima, R.E. Boto, D. Ferreira, J.R. Fernandes, P.Almeida, Luis F. V. Ferreira, A.M. Silva, L.V. Reis, Red and Near-Infrared Absorbing Dicyanomethylene Squaraine Cyanine Dyes: Photophysicochemical Properties and Anti-Tumor Photosensitizing Effects, Materials 13 (2020) 2083. 
[193] D. Zhang, Y.-X. Zhao, Z.-Y. Qiao, U. Mayerhöffer, P. Spenst, X.-J. Li, F. Würthner, H. Wang, Nano-Confined Squaraine Dye Assemblies: New Photoacoustic and Near-Infrared Fluorescence Dual-Modular Imaging Probes in Vivo, Bioconjugate Chem. 25 (2014) 2021-2029.

[194] T. Tanabe, A. Torres-Filho, D.C. Neckers, Visible light photopolymerization: Synthesis of new fluorone dyes and photopolymerization of acrylic monomers using them, J. Polym. Sci., Part A: Polym. Chem. 36 (1995) 1691-1703.

[195] T. Mori, K. Miyachi, T. Kichimi, Electrical and Luminescent Properties of Color-Changeable Organic Electroluminescent Diode Using Squarylium Dyes, Jpn. J. Appl. Phys. 33 (1994) 6594.

[196] R.W. Bigelow, H.J. Freund, An MNDO and CNDO / S(S + DES CI) study on the structural and electronic properties of a model squaraine dye and related cyanine, Chem. Phys. 107 (1986) 159174 .

[197] W. Zhou, E. Wang, Photoinduced electron transfer in the ion pair compound (XTOn): influence of ionic association, J. Photochem. Photobiol. A: Chem. 96 (1996) 25-29.

[198] Y. Bi, D.C. Neckers, Photochemical reaction of halogenated xanthene dye with diaryliodonium salts, J. Photochem. Photobiol. A: Chem. 74 (1993) 221-230.

[199] J. Kabatc, K. Kostrzewska, K. Jurek, Squaric acid derivative effects on the kinetics of photopolymerization of different monomers, RSC Adv. 6 (2016) 74715-74725.

[200] K. Kostrzewska, J. Ortyl, R. Dobosz, J. Kabatc, Squarylium dye and onium salts as highly sensitive photoradical generators for blue light, Polym. Chem. 8 (2017) 3464-3474.

[201] W. Schnabel, in Polymers and light. Fundamentals and technical application, Wiley-VCH, Weinheim, 2007, pp. 275-329.

[202] J.V. Crivello, M. Sangermano, Visible and long-wavelength photoinitiated cationic polymerization, J. Polym. Sci., Part A: Polym. Chem., 2001, 39, 343-356.

[203] J. Kabatc, K. Kostrzewska, M. Kozak, A. Balcerak, Visible light photoinitiating systems based on squaraine dye: kinetic, mechanistic and laser flash photolysis studies, RSC Adv. 6 (2016) 103851-103863.

[204] G. Temel, B. Enginol, M. Aydin, D.K. Balta, N. Arsu, Photopolymerization and photophysical properties of amine linked benzophenone photoinitiator for free radical polymerization, $\mathrm{J}$. Photochem. Photobiol., A, 2011, 219, 26-31.

[205] J. Kabatc, J. Ortyl, K. Kostrzewska, New kinetic and mechanistic aspects of photosensitization of iodonium salts in photopolymerization of acrylates, RSC Adv. 7 (2017) 41619-41629

[206] J. Kabatc, K. Kostrzewska, R. Dobosz, Ł. Orzeł, K. Jurek, N-Alkoxypyridinium Salts as Coinitiators in Radical Polymerization, Synthesis and Photochemical Properties, J. Polym. Sci A Polym. Chem. 55 (2017) 2840-2850

[207] J. Kabatc, K. Kostrzewska, K. Jurek, M. Kozak, A. Balcerak, Ł. Orzeł, New Squaraine-Based TwoComponent Initiation Systems for UV-Blue Light Induced Radical Polymerization: Kinetic and Time-Resolved Laser Spectroscopy Studies, J. Polym. Sci A Polym. Chem. 55 (2017) 471-484. 
[208] A. Balcerak, D. Kwiatkowska, K. Iwińska, J. Kabatc, Highly efficient UV-Vis light activated three-component photoinitiators composed of tris(trimethylsilyl)silane for polymerization of acrylates, Polym. Chem. 11 (2020) 5500-5511.

[209] J.-P. Fouassier, F. Morlet-Savary, J. Lalevée, X. Allonas, C. Ley, Dyes as Photoinitiators or Photosensitizers of Polymerization Reactions, Materials 3 (2010) 5130-5142.

[210] J. Lalevée, A. Dirani, M. El-Roz, X. Allonas, J.-P. Fouassier, Silanes as New Highly Efficient Coinitiators for Radical Polymerization in Aerated Media, Macromolecules 41 (2008) 2003-2010.

[211] Y. Chen, Q. Jia, Y. Ding, S. Sato, L. Xu, C. Zang, X. Shen, T. Kakuchi, B( $\left.\mathrm{C}_{6} \mathrm{~F}_{5}\right)_{3}$-Catalyzed Group Transfer Polymerization of Acrylates Using Hydrosilane: Polymerization Mechanism, Applicable Monomers, and Synthesis of Well-Defined Acrylate Polymers, Macromolecules 52 (2019) 844-856.

[212] J. Lalevée, M. El-Roz, X. Allonas, J.-P. Fouassier, Surface modification of a UV curable acrylate coating: In situ introduction of hydrophobic properties, Prog. Org. Coat. 65 (2009) 457-461.

[213] J. Steindl, T. Koch, N. Moszner, C. Gorsche, Silane-Acrylate Chemistry for Regulating Network Formation in Radical Photopolymerization, Macromolecules 50 (2017) 7448-7457.

[214] J. Lalevée, M.A. Tehfe, F. Morlet-Savary, B. Graff, X. Allonas, J.-P. Fouassier, Oxygen mediated and wavelength tunable cationic photopolymerization reactions under air and low intensity: A new concept, Prog. Org. Coat. 70 (2011) 23-31.

[215] D. Wang, P. Garra, J.-P. Fouassier, J. Lalevée, Silane/iodonium salt as redox/thermal/photoinitiating systems in radical and cationic polymerizations for laser write and composites, Polym. Chem. 11 (2020) 857-866.

[216] L. Song, Q. Ye, X. Ge, A. Misra, P. Spencer, Tris(trimethylsilyl)silane as a co-initiator for dental adhesive: Photo-polymerization kinetics and dynamic mechanical property, Dent. Mater. 32 (2016) 102-113.

[217] M. A. Tehfe, M. El-Roz, J. Lalevée, F. Morlet-Savary, B. Graff, J.-P. Fouassier, Bifunctional coinitiators: A new strategy for the design of efficient systems in radical photopolymerization reactions under air, Eur. Polym. J. 48 (2012) 956-962.

[218] J. Kabatc, K. Iwinska, A. Balcerak, D. Kwiatkowska, A. Skotnicka, Z. Czech, M. Bartkowiak, Onium salts improve the kinetics of photopolymerization of acrylate activated with visible light, RSC Adv. 10 (2020) 24817-24829.

[219] T. Geiger, S. Kuster, J.-H. Yum, S.-J. Moon, M.K. Nazeeruddin, M. Gratzel, F. Nuesch, Molecular Design of Unsymmetrical Squaraine Dyes for High Efficiency Conversion of Low Energy Photons into Electrons Using TiO2 Nanocrystalline Films, Adv. Funct. Mater. 19 (2009) 2720 2727.

[220] X. Wang, J. Xu, M. Li, D. Fang, B. Chen, L. Wang, W. Xu, Highly efficient unsymmetrical squaraines for panchromatic dye-sensitized solar cells: A computational study, RSC Adv. 3 (2013) 5227-5237. 
[221] P. Xiao, F. Dumur, T.-T. Bui, F. Goubard, B. Graff, F. Morlet-Savary, J.-P. Fouassier, D. Gigmes, J. Lalevée, Panchromatic Photo-polymerizable Cationic Films Using Indoline and Squaraine Dye Based Photoinitiating Systems, ACS Macro Lett. 2 (2013) 736-740.

[222] S. Zhang, B. Li, L. Tang, X. Wang, D. Liu, Q. Zhou, Studies on the near infrared laser induced photopolymerization employing a cyanine dye-borate complex as the photoinitiator, Polymer 42 (2001) 7557-7582.

[223] A.-H. Bonardi, F. Bonardi, F. Morlet-Savary, C. Dietlin, G. Noirbent, T. M. Grant, J.-P. Fouassier, F. Dumur, B. H. Lessard, D. Gigmes, J. Lalevée, Photoinduced Thermal Polymerization Reactions, Macromolecules 51 (2018) 8808-8820.

[224] P. Atkins, Elements of Physical Chemistry, W.H. Freeman, New York, 3rd edn, 1986.

[225] C. Schmitz, B. Strehmel, Photochemical Treatment of Powder Coatings and VOC-Free Coatings with NIR Lasers Exhibiting Line-Shaped Focus: Physical and Chemical Solidification, ChemPhotoChem 1 (2019) 26-34.

[226] C. Schmitz, A. Halbhuber, D. Keil, B. Strehmel, NIR-Sensitized Photoinitiated Radical Polymerization and Proton Generation with Cyanines and LED Arrays, Prog. Org. Coat. 100 (2016) 32-46.

[227] B. Strehmel, T. Brömme, C. Schmitz, K. Reiner, S. Ernst, D. Keil, NIR-Dyes for Photopolymers and Laser Drying in the Graphic Industry, Dyes and Chromophores in Polymer Science, 2015, pp. 213-249.

[228] T. Brömme, C. Schmitz, N. Moszner, P. Burtscher, N. Strehmel and B. Strehmel, Photochemical Oxidation of NIR Photosensitizers in the Presence of Radical Initiators and Their Prospective Use in Dental Applications, ChemistrySelect 1 (2016) 524-532.

[229] C. Kütahya, C. Schmitz, V. Strehmel, Y. Yagci, B. Strehmel, Near-Infrared Sensitized Photoinduced ATRP with Ppm of Cu(II) Catalyst, Angew. Chem. 25 (2018) 7898-7902.

[230] C. Kütahya, Y. Yagci, B. Strehmel, Photoinduced Copper Catalyzed Azide-Alkyne Click Chemistry with a Cyanine Comprising a Barbiturate Group at 790 Nm, ChemPhotoChem 3 (2019) 1180-1186.

[231] C. Schmitz, Y. Pang, A. Gülz, M. Gläser, J. Horst, M. Jaeger, B. Strehmel, New High-Power LED Opens Photochemistry for Near Infrared Sensitized Radical and Cationic Photopolymerization, Angew. Chem. 58 (2019) 4400-4404.

[232] C. Schmitz, B. Strehmel, NIR LEDs and NIR Lasers as Feasible Alternatives to Replace Oven Processes for Treatment of Thermal-Responsive Coatings, J. Coat. Technol. Res. 16 (2019) 15271541.

[233] A. Shiraishi, H. Kimura, D. Oprych, C. Schmitz, B. Strehmel, Comparison between NIR and UVSensitized Radical and Cationic Reactivity of Iodonium Salts Comprising Anions with Different Coordination Behavior, J. Photopolym. Sci. Technol. 30 (2017) 633-638. 
[234] B. Strehmel, C. Schmitz, T. Brömme, A. Halbhuber, D. Oprych, J. Gutmann, Advances of Near Infrared Sensitized Radical and Cationic Photopolymerization: From Graphic Industry to Traditional Coatings, J. Photopolym. Sci. Technol. 29 (2016) 111-121.

[235] K. Shimada, T. Sorori, M. Yagihara, Photosensitive Composition and Planographic Printing Plate Precursor, Google Patents, 2004.

[236] J. Fabian, H. Nakazumi, M. Matsuoka, Near-Infrared Absorbing Dyes, Chem. Rev. 92 (1992) 1197-1226.

[237] N. Fernandes, C.F. Rodrigues, A.F. Moreira, I.J. Correia, Overview of the application of inorganic nanomaterials in cancer photothermal therapy, Biomater. Sci. 8 (2020) 2990-3020.

[238] M. Abbasian, F. Mahmoodzadeh, R. Salehi, A. Amirshaghaghi, Chemo-photothermal therapy of cancer cellsusing gold nanorod-cored stimuli-responsive triblock copolymer, New J. Chem. 41 (2017) 12777-12788

[239] S. Li, Z. Sun, G. Deng, X. Meng, W. Li, D. Ni, J. Zhang, P. Gong, L. Cai, Dual-modal imagingguided highly efficientphotothermal therapy using heptamethinecyanine-conjugated hyaluronic acid micelles, Biomater. Sci. 5 (2017) 1122-1129.

[240] A. Yuan, J. Wu, X. Tang, L. Zhao, F. Xu, Y. Hu, Application of Near-Infrared Dyes for Tumor Imaging, Photothermal, and Photodynamic Therapies, J. Pharm. Sci. 102 (2013) 6-28.

[241] Y. Jiyang, X. Duan, J. Bai, H. Tian, D. Ding, Y. Geng, Polymerization-induced photothermy: A non-donor-acceptor approach to highly effective near-infrared photothermal conversion nanoparticles, Biomaterials 255 (2020) 120179.

[242] X. Zhang, Z. Si, Y. Wang, Y. Li, C. Xu, H. Tian, Polymerization and coordination synergistically constructed photothermal agents for macrophages-mediated tumor targeting diagnosis and therapy, Biomaterials 264 (2021) 120382

[243] K. Matyjaszewski, B.E. Woodworth, X. Zhang, S.G. Gaynor, Z. Metzner, Simple and efficient synthesis of various alkoxyamines for stable free radical polymerization, Macromolecules 31 (1998) 5955-5957.

[244] D. Bertin, D. Gigmes, S.R.A. Marque, P. Tordo, Kinetic subtleties of nitroxide mediated polymerization, Chem. Soc. Rev. 40 (2011) 2189-2198.

[245] F. Chauvin, P.E. Dufils, D. Gigmes, Y. Guillaneuf, S.R.A. Marque, P. Tordo, D. Bertin, Nitroxidemediated polymerization: The pivotal role of the kd value of the initiating alkoxyamine and the importance of the experimental conditions, Macromolecules 39 (2006) 5238-5250.

[246] Plastics: the Facts, www.plasticseurope.org (accessed: February 2020).

[247] Plastics: the Facts, www.plasticseurope.org (accessed: February 2020).

[248] J. Maris, S. Bourdon, J.-M. Brossard, L. Cauret, L. Fontaine, V. Montembault, Mechanical recycling: Compatibilization of mixed thermoplastic wastes, Polym. Degrad. Stab. 147 (2018) 245-266. 